\title{
Recent developments in the production of liquid fuels via catalytic conversion of microalgae: experiments and simulations
}

\author{
Fan Shi, ${ }^{* a b}$ Ping Wang, ${ }^{a}$ Yuhua Duan, ${ }^{* a}$ Dirk Link $^{a}$ and Bryan Morreale ${ }^{a}$
}

Received 27th July 2012, Accepted 31st July 2012

DOI: $10.1039 / \mathrm{c} 2 \mathrm{ra21594b}$

Due to continuing high demand, depletion of non-renewable resources and increasing concerns about climate change, the use of fossil fuel-derived transportation fuels faces relentless challenges both from a world markets and an environmental perspective. The production of renewable transportation fuel from microalgae continues to attract much attention because of its potential for fast growth rates, high oil content, ability to grow in unconventional scenarios, and inherent carbon neutrality.

Moreover, the use of microalgae would minimize "food versus fuel" concerns associated with several biomass strategies, as microalgae do not compete with food crops in the food chain. This paper reviews the progress of recent research on the production of transportation fuels via homogeneous and heterogeneous catalytic conversions of microalgae. This review also describes the development of tools that may allow for a more fundamental understanding of catalyst selection and conversion processes using computational modelling. The catalytic conversion reaction pathways that have been investigated are fully discussed based on both experimental and theoretical approaches. Finally, this work makes several projections for the potential of various thermocatalytic pathways to produce alternative transportation fuels from algae, and identifies key areas where the authors feel that computational modelling should be directed to elucidate key information to optimize the process.

\section{Introduction}

With the rapid development of modern civilization, national energy security, availability and affordability, as well as environmental impact are major drivers for developing renewable energy sources, such as biofuels, bioproducts and biopower. ${ }^{1}$ During recent decades, sustainable energy sources have been widely researched to meet such challenges. Among these efforts, liquid biofuels from renewable bio-resources are one of the most attractive alternatives, with the features of sustainability and the

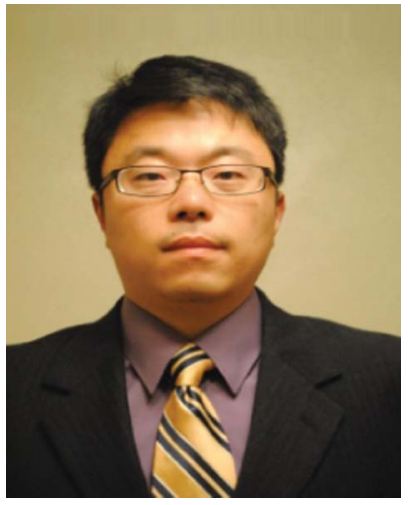

Fan Shi
Dr Fan Shi is a senior materials scientist of URS Corporation working at the Department of Energy's (DOE) National Energy Technology Laboratory (NETL). Dr Shi has been actively working on sustainable energy production and greenhouse gas separation for more than 10 years. He is also working on two books focusing on sustainable energy research. Dr Shi obtained his BS and $M S$ in chemical engineering from the Nanjing University of Technology, China. He holds a Ph.D. in chemical engineering from the University of Pittsburgh.

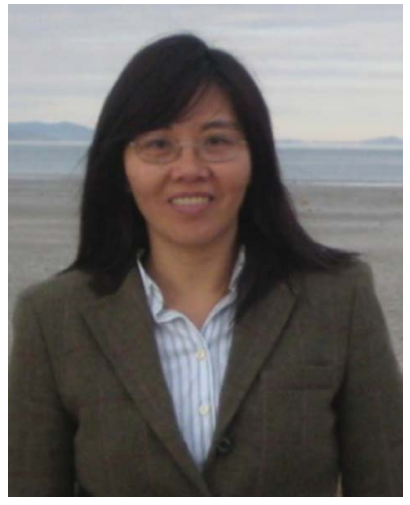

Dr Ping Wang is a chemical and biological engineer at the U.S.A. DOE-NETL in Pittsburgh, PA. Her research interests are in the areas of biomass and coal from their preparation and characterization to their conversion to gaseous/liquid fuels. Prior to joining NETL, she had many years experience with grain based liquid fuel process development at the University of Illinois at UrbanaChampaign (UIUC) in Urbana, IL. She earned her Ph.D. in Ping Wang Agricultural and Biological Engineering from UIUC. 
ability to utilize current infrastructure (i.e. pipelines, vehicle engines, etc.). ${ }^{1-6}$

In the United States, petroleum accounts for approximately $90 \%$ of the energy consumed within the transportation sector, and this usage reflects nearly $70 \%$ of the oil processed nationally. ${ }^{1}$ In addition, the large consumption of petroleumbased transportation fuels accounts for roughly one-third of $\mathrm{CO}_{2}$ emissions, which is thought to be a major contributor to global climate change. ${ }^{1}$ With increasing demand but limited fossil fuel resources, as well as growing concerns about national energy security and climate change, the production of transportation fuels via alternative renewable routes, especially from relatively inexpensive and plentiful photosynthetic organisms as feedstocks, is becoming more important for addressing future energy needs. Biomass, especially algae based biomass, has been considered as a potential alternative feedstock for the production of traditional petroleum-based commodities, including transpor-

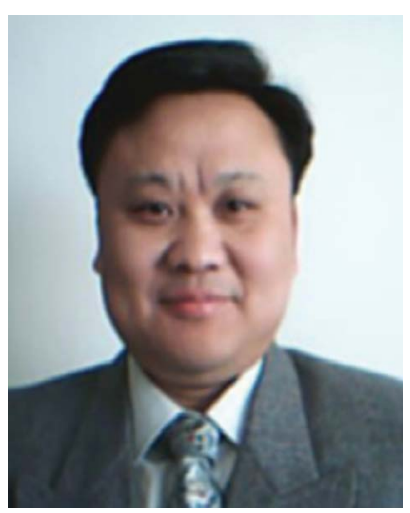

Yuhua Duan

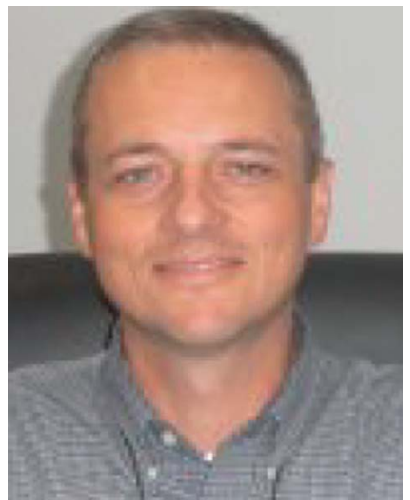

Dirk Link
Dr Yuhua Duan is a physical scientist at the U.S. DOE-NETL. He obtained his BS in Chemistry, a MS in Chemical Physics, Ph.D. in Condensed Matter of Physics from the University of Science and Technology of China, and another $M S$ in Computer Engineering from the University of Minnesota. Dr Duan has authored and coauthored more than 60 publications. His research interests include developing technologies for $\mathrm{CO}_{2}$ capture and energetic materials applied to batteries and solar cells, exploring the mechanisms of biological enzyme catalysis and high-temperature gas sensors, and multi-scale modelling of energy systems. tation fuels. ${ }^{7-11}$ In addition, diversifying the energy portfolio to include more renewable energy resources can assist in overcoming impacts associated with increased greenhouse gas concentrations in the atmosphere. ${ }^{1,12,13}$

Biomass, including agricultural residues, forest resources, energy crops, wastes and algae, is an opportunistic renewable resource that can be converted to liquid transportation fuels in the near-term. ${ }^{1}$ Current trends show that the United States biofuel production for transportation will continually increase over the next few decades, as shown in Fig. 1. ${ }^{1}$ In the United States, the Energy Independence and Security Act (EISA) of 2007 requires production of 36 billion gallons per year (bgy) of renewable transportation fuels by $2022 .^{1}$ The United States Environmental Protection Agency's (EPA) final rule projects that these renewable fuels could come from starch-based ethanol and advanced biofuels including cellulosic ethanol, biobutanol, hydrocarbons from algae and biomass-based hydrocarbon fuels (renewable gasoline, diesel, jet fuel). ${ }^{1,7,11}$

Algae, including microalgae and macroalgae (such as seaweed), is currently commercially used in food and other products and has potential as a carbon-neutral feedstock for biofuel production. ${ }^{11,14-21}$ Among renewable biomass resources for

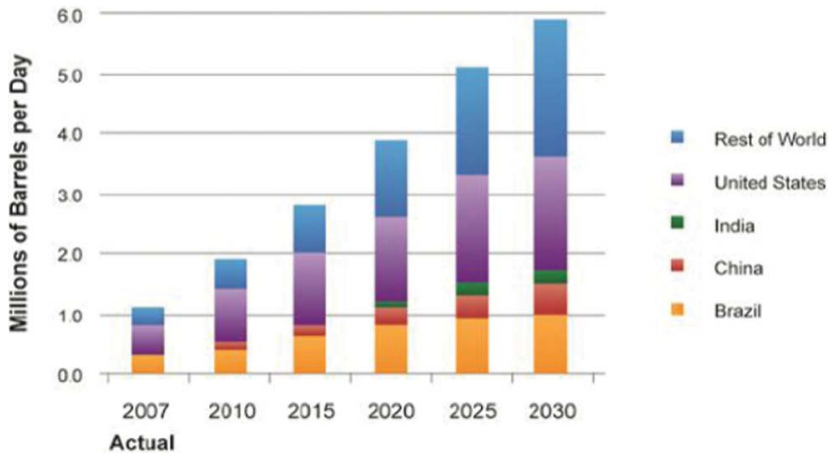

Fig. 1 Biofuels production worldwide. ${ }^{1}$
Dr Dirk Link received his Ph.D. in Analytical Chemistry from Duquesne University. His initial research at U.S. DOE was in trace analysis of sulfur species in liquid fuels, and structure-performance relationships for sulfur species. His experience broadened to other polar species in fuels, as well as biological sources for alternative fuels, primarily microalgae. $\mathrm{Dr}$ Link has developed protocols to accurately assess the lipid content of fuels using a combination of extraction and conversion, and has shown that gravimetric lipid determination can dramatically overstate the lipid content of algae. This, in turn, affects the projections of potential yield of lipidbased fuels.

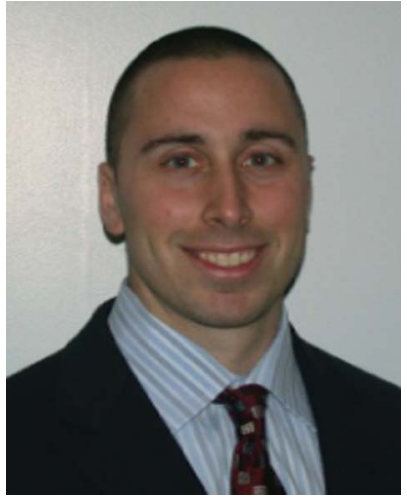

Dr Bryan Morreale is the acting Materials Science and Engineering focus area lead within the Office of Research and Development at the DOE-NETL. Dr Morreale leads activities across a diverse research portfolio related to both structural and functional materials for advanced energy conversion applications, specifically focused on advanced gasification, advanced combustion and minimizing environmental impacts. Dr Morreale's tenure at NETL began in 1999, where he supports the NETL Office of Research and Development as well as the NETL Strategic Center for Coal. 
advanced biofuels, microalgae continues to attract attention because of its potential for fast growth rates, high oil yield (1000$6500 \mathrm{gal} \mathrm{acre}^{-1} \mathrm{yr}^{-1}$ vs. soybean $48 \mathrm{gal} \mathrm{acre}^{-1} \mathrm{yr}^{-1}$ ), the use of non-arable land for algae cultivation, growth in a variety of water sources and the benefits associated with large-scale $\mathrm{CO}_{2}$ mitigation. ${ }^{3,6,11,14-19}$ Furthermore, microalgae-based biofuels do not compete with food crop production, unlike conventional biofuels, which typically use fertile land and edible oils in their production cycle. Research supported by the U.S. Department of Energy is studying the potential use of microalgae to produce biodiesel with $\mathrm{CO}_{2}$ captured from point sources, including coal fired power plants. ${ }^{22-27}$ Microalgae are able to produce more than $50 \%$ dry weight of bio-crude oil with the potential to yield 100 -times higher oil production than conventional crops. ${ }^{28}$ The compositions of typical microalgal oils include higher molecular weight species ranging from $\mathrm{C} 14$ to $\mathrm{C} 26$, and often contain carboxylic acids. Overall, the bio-oil has a chemical nature and energy density comparable to that of petroleum-based diesel, making algae oil-based biofuels a target for diesel replacement. ${ }^{29}$ Microalgae-based oil also typically contains from $20 \%$ to $50 \%$ free fatty acids. ${ }^{30,31}$

The three major components of microalgae are carbohydrates, lipids and proteins. ${ }^{15}$ The lipid content of dry biomass of various microalgae species varies from $4 \%$ (such as in spirulina) to as high as $80 \%$ (such as in botyococcus braunii). ${ }^{18}$ Depending on the species of microalgae, three major pathways can be used to convert it to transportation fuel, including whole algae conversions (thermochemical conversion), lipid (algal oil) extraction followed by catalytic reactions (thermochemical conversion), and hydrolysis of carbohydrates (biochemical conversion), as shown in Fig. 2. 1,14,32 Because the aim of this work is to focus on the thermocatalytic conversion of microalgae, the hydrolysis of carbohydrates and fermentation of sugar to ethanol will not be discussed further.

Whole microalgae can be processed into fuels directly via gasification, pyrolysis, and hydrothermal liquefaction (HTL). ${ }^{14,32-35}$ The gasification or partial oxidation of microalgae in the presence of steam produces an intermediate synthesis gas $\left(\mathrm{H}_{2}\right.$ and $\left.\mathrm{CO}\right)$ that can be further converted via thermocatalytic pathways to liquid fuels and chemicals. ${ }^{1,14,34,36,37}$ Microalgae can also be converted thermochemcially in the absence of oxygen, where the pyrolysis (fast pyrolysis, $450-550{ }^{\circ} \mathrm{C}$ and $10^{3}-10^{4}{ }^{\circ} \mathrm{C}$ $\mathrm{s}^{-1}$ ) generates bio-oil with less oxygen content and higher heating values than lignocellulosic based bio-oil, ${ }^{38,39}$ which is upgraded to transportation fuels by thermocatalytic processes. ${ }^{14,34,37,40-42}$ High water content (as high as $\left.92 \%\right)^{43}$ in harvested microalgae makes HTL processes more economically attractive than pyrolysis, gasification or extraction methods, all of which require an energy-intensive pre-drying procedure. ${ }^{34,44,45}$ The resulting bio-crude oil is subsequently fed into the refinery stream and upgraded via conventional petroleum catalytic processes to transportation fuel through cracking, hydrocracking and hydro-deoxygenation using commercial catalysts.

For the microalgae extraction pathway, 45\% lipid content is estimated as the "optimistic case", based on energy needed from microalgae production to biodiesel. ${ }^{33}$ The residues remaining after lipid extraction could potentially be converted into biofuel by carbohydrate hydrolysis and fermentation to obtain an optimized yield, productivity and process efficiency. ${ }^{1,14}$ Selective conversion of triacylglycerides and free fatty acids (FFAs) to transportation fuels from lipids produced by microalgae has received extensive attention due to environmental concerns and high demand for transportation fuels. Traditional biodiesel fuels, i.e., fatty acid methyl esters (FAME), from renewable resources

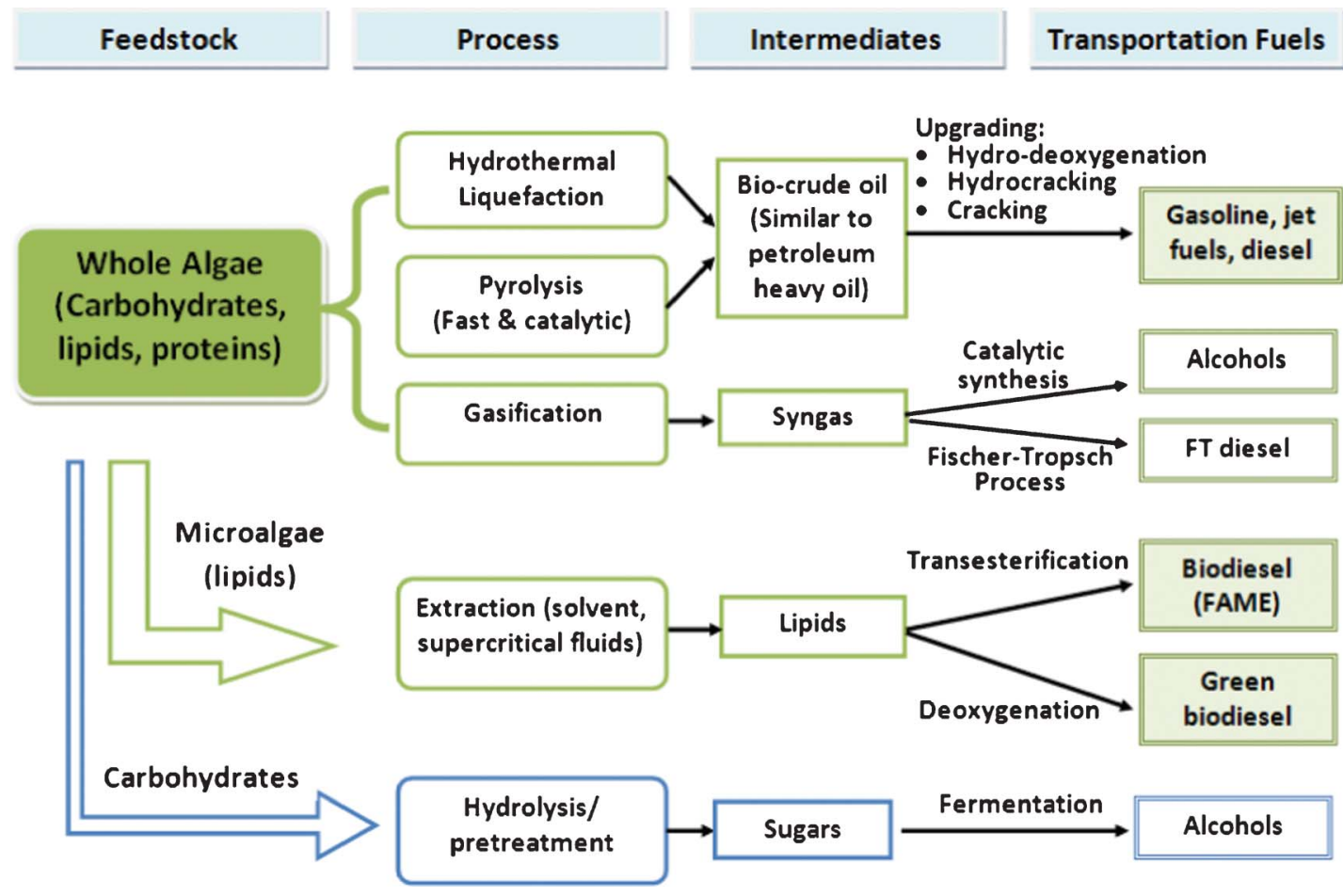

Fig. 2 Pathways for converting microalgae to biofuels. ${ }^{1,14}$ 
including microalgae, are generally produced via transesterification reactions in solvents using homogeneous catalysts. ${ }^{36,37,40-42,46}$ However, due to undesirable oxygen groups present in biofuels compared to petroleum-derived diesel fuels, these conventional biodiesels suffer from the propensity to have lower energy densities and poor low-temperature properties, and they absorb water, and are also susceptible to microbial fouling. ${ }^{31,47,48}$ In addition, a large quantity of the by-product from the transesterification reactions, specifically the glycerol, is rapidly being considered as a waste material. However, a new generation of green diesels produced from microalgae ${ }^{49-51}$ are alkane hydrocarbons similar to those found in conventional fossil fuel-derived fuels, thus making them fully compatible with existing engines and infrastructure. This green diesel from microalgae also produces fewer by-products, such as the waste glycerol produced from transesterification. While many examples of the growth and extraction of the resultant microalgae are available in the literature, ${ }^{4,21,31,52-56}$ instances discussing the upgrade or catalytic conversion of microalgal lipids to alkane-based transportation fuels are relatively sparse and not discussed extensively.

Among the major stages for the production of algal biofuel, as shown in Fig. 2, are several factors that need to be considered and optimized, including energy and material inputs. Computational modelling can be applied to each of these stages to identify the optimizing conditions for algal biofuel technology development. However, of the relatively few simulations found in the literature, many focused only on the microalgae growth, specifications, and harvesting process, 3,4,6,12,15,21,31,52-61 and very few discussed the catalytic conversion of algal oils to fuel, especially using the computational modelling approach. Most simulation studies were done for model compounds, which are only indirectly related to the catalytic conversion of a complex biological mixture like algal oils.

In this review, we summarize both the experimental studies of the catalytic conversion of microalgae to transportation fuels and the studies that provide a fundamental understanding of the processes using computational simulation. To address the importance of computational modelling in the field of biofuel production, we also summarize the modelling progress in hydrocracking, decarboxylation, and hydrodeoxygenation of model compounds. This review is organized as follows: section two summarizes the progress in HTL of microalgae to bio crude oil; section three describes progress on transesterification of algae to FAME; section four summarizes the current status of the catalytic upgrading of algae feedstock to liquid fuels and the model compounds typically used as surrogates for lipid-rich microalgae; and finally, some perspectives and concluding remarks are given in section five.

\section{HTL of microalgae to bio-crude oil}

HTL generally converts biomass to bio-crude oil in subcritical water (below the water critical point of $374{ }^{\circ} \mathrm{C}$ and $22 \mathrm{MPa}$ ). ${ }^{44,62}$ Bio-crude oil is much like a petroleum-derived product but with a higher viscosity and oxygen content, typically $10-20 \mathrm{wt} \%$ compared to $<1 \%$ in conventional petroleum. ${ }^{44}$ Therefore, biocrude-oil requires upgrading by removing oxygenates and reducing molecular weight to produce transportation fuel. ${ }^{63}$ Many studies ${ }^{37,44,64-73}$ report use of the HTL process for conversion of biomass to fuels. In the 1970s, pioneering work on the HTL of cellulosic biomass using a sodium carbonate catalyst to produce a heavy oil was conducted by researchers at the Pittsburgh Energy Research Center. ${ }^{64}$ A liquefaction pilot plant capable of treating 3 tons per day of biomass was demonstrated in Albany, Oregon. ${ }^{66}$ One of the pioneering works on HTL for microalgae (Botryococcus braunii) with high lipid content was done by Dote et al. in $1994 .^{74}$ Since then, HTL has been applied to a wide range of lipid contents of microalgae $(<1$ to $50 \%$ of total microalgae) ${ }^{74-81}$ microalgae residues (e.g. from post-lipid extraction $)^{82-83}$ and macroalgae. ${ }^{73,84-85}$ Sawayama et al. $^{86}$ studied energy consumption for the HTL of various microalgae and presented it as an energy consumption ratio (ECR) that represents energy for liquefaction and the lowest heating value of the oil production. They found that ECRs were low, less than 1.0, which means that HTL of microalgae could produce net energy. ${ }^{86}$ Therefore, HTL has been considered as a promising technology to generate liquid fuel from wet biomass. In this section, we summarize the current progress on HTL for converting whole algae to bio-crude-oil.

\subsection{Microalgae composition and conversions in HTL conditions}

Microalgae are single-celled organisms that include both eukaryotic cells and prokaryotic cells (cyanobacteria, also called blue-green algae). ${ }^{15,56}$ The enormous number of microalgae species is divided into groups, with the most important including green algae (Chlophyceae), red algae (Rhodophyceae), and diatoms (Bacillariophyta). ${ }^{15,18}$ Microalgae have three major components: carbohydrates, lipids and proteins. ${ }^{15}$ Table 1 lists the biochemical and chemical compostions of selected species of microalgae reported in the literature. Microalgae can be classified as having low (15\% of total mass), medium $(25 \%)$ and high $(50 \%)$ lipid contents. ${ }^{15}$

Carbohydrates are monosaccharide polymers with an elemental composition $\mathrm{C}_{1} \mathrm{H}_{1.67} \mathrm{O}_{0.83}, 17.3 \mathrm{MJ} \mathrm{kg}^{-1}$ of calculated calorific value and $10-50 \%$ of typical cell content. ${ }^{15}$ Sugars (monosaccharide and disaccharide) and starches (polysaccharides in the form of amylose and amylopectin) are all carbohydrates. Different polysaccharides belong to different groups of microalgae, e.g. starch consisting of amylose and amlopectin is in green algae as an energy store and floridean starch consisting mostly of amylose is in red algae. In the HTL conditions (subcritical water system), starch is rapidly hydrolyzed to monosaccharides with glucose as one of the main products. As shown in Fig. 3, the glucose is readily converted to fructose, an isomer of glucose. ${ }^{87}$ This fructose subsequently undergoes degradation with fragmenation procucts e.g. glycolaldehyde and glyceraldehyde. Further fragmentaion and dehydrations produce complex products e.g. acetic acid, formic acid and aromatic compounds. ${ }^{44,87}$

Most proteins consist of linear polymers of amino acids with an elemental composition of $\mathrm{C}_{1} \mathrm{H}_{1.56} \mathrm{O}_{0.3} \mathrm{~N}_{0.26} \mathrm{~S}_{0.006}, 23.9 \mathrm{MJ} \mathrm{kg}{ }^{-1}$ of calculated calorific value, and $20-60 \%$ of typical cell content. ${ }^{15}$ They have both structural and metabolic functions. The peptide $\mathrm{C}-\mathrm{N}$ bond links the amino acids together between the carboxyl and amine groups. The bond will be hydrolyzed under hydrolysis conditions and results in production of amino acids with optimal 
Table 1 The biochemical and chemical compositions of microalgae

\begin{tabular}{|c|c|c|c|c|c|c|c|c|c|c|c|}
\hline \multirow[b]{2}{*}{ Microalgae } & \multicolumn{3}{|c|}{ Biochemical composition (daf \%) } & \multirow{2}{*}{$\begin{array}{l}\text { Proximate } \\
\text { Ash }(\mathrm{db} \%)^{a}\end{array}$} & \multicolumn{5}{|c|}{ Ultimate (daf \%) } & \multirow{2}{*}{$\begin{array}{l}\text { High heating value } \\
\left(\mathrm{MJ} \mathrm{kg}^{-1}\right)\end{array}$} & \multirow{2}{*}{ Refs } \\
\hline & Lipid/Crude fat & Crude protein & Carbohydrate & & $\mathrm{C}$ & $\mathrm{H}$ & $\mathrm{N}$ & $\mathrm{O}^{b}$ & S & & \\
\hline Botryococcus braunii & 50 & - & - & 2 & 63.1 & 11.7 & 2.8 & 22.4 & - & - & 74 \\
\hline Nannochloropsis sp. ${ }^{c}$ & 28 & 52 & 12 & - & 43.3 & 6 & 25.1 & 6.4 & 0.5 & - & 77 \\
\hline Chlorella vulgaris & 25 & 55 & 9 & 7 & 52.6 & 7.1 & 8.2 & 32.2 & 0.5 & 23.2 & 76 \\
\hline Dunaliella tertiolecta & 20.5 & 63.6 & 14.7 & 23.6 & 53.3 & 5.2 & 9.8 & 31.7 & - & - & 78 \\
\hline Desmodesmus sp. & $10-14$ & $38-44$ & $13-20$ & - & 51.96 & 7.31 & 6.86 & 33.87 & - & 23.44 & 88 \\
\hline Spirulina platensis & 13.1 & 65.38 & - & 6.6 & 46.87 & 6.98 & 10.75 & 34.86 & 0.54 & 20.52 & 89 \\
\hline Scenedesmus ${ }^{c}$ & 13 & 56 & 25 & 6 & 52.1 & 7.4 & 8.8 & 31.1 & 0.48 & 22.6 & 82 \\
\hline Porphyridium cruentum & 8 & 43 & 40 & 24.4 & 51.3 & 7.6 & 8 & 33.1 & - & 14.7 & 76 \\
\hline Cyanobacteria (Spirulina) & 5 & 65 & 20 & 7.6 & 55.7 & 6.8 & 11.2 & 26.4 & 0.8 & 21.2 & 76 \\
\hline Cyanobacteria $\left(\right.$ Spirulina) ${ }^{c}$ & 5 & 64 & 20 & 11 & 45.2 & 6.4 & 9.8 & 37.8 & 0.8 & 17.7 & 82 \\
\hline Cyanobacteria $\left(\right.$ Spirulina) ${ }^{c}$ & 12 & 57.5 & $<0.5$ & - & 46.1 & 7.4 & 4.8 & 41.3 & 0.4 & -1 & 90 \\
\hline
\end{tabular}

${ }^{a}$ Organic content $=100-$ ash content ${ }^{b}$ By difference ${ }^{c}$ On dry basis for biochemical composition and ultimate analysis ${ }^{d}$ Residues after recovering $\beta$-carotene as a bioactive compound

yields at $\sim 250{ }^{\circ} \mathrm{C} .{ }^{44}$ The peptide bonds of proteins are more stable than the glycosidic bonds in starch, and peptide bond hydrolysis occurs slowly below $230{ }^{\circ} \mathrm{C}$. ${ }^{87}$ The amino acids rapidly undergo decarboxylation and deamination and produce mainly hydrocarbons, amines, aldehydes and acids. ${ }^{44,87}$ Some of these products are the same as those from hydrolysis of carbohydrate. Thus, similar condensation may take place in protein degradation alone or together with carbohydrate degradation, in the case of HTL of algae as shown in Fig. 3. ${ }^{87}$ In addition, a considerable fraction of the nitrogen in protein will be incorporated in the bio-oil during the HTL process. The nitrogen in oil causes $\mathrm{NO}_{x}$ emission when it is combusted.

Algal lipids mainly consist of simple fatty acid triglycerides (TAG), glycolipids and a phospholipid with elemental compositions of $\mathrm{C}_{1} \mathrm{H}_{1.83} \mathrm{O}_{0.17} \mathrm{~N}_{0.0031} \mathrm{P}_{0.006} \mathrm{~S}_{0.0014}, 36.3 \mathrm{MJ} \mathrm{kg} \mathrm{kg}^{-1}$ of calculated calorific value and $15-60 \%$ of typical cell content. ${ }^{15}$

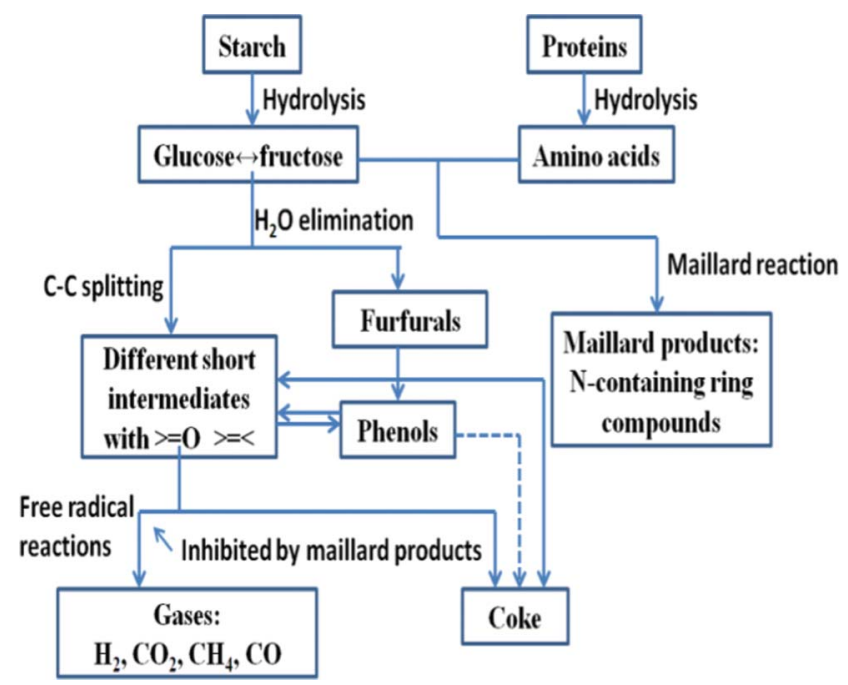

Fig. 3 Simplified reaction pathways for hydrothermal carbohydrate and proteins, adapted from reference 87 .
The lipids can function as the structural membranes of the cells. The prokaryotic algae (cyanobacteria) has less lipid content compared to eukaryotic algae, possibly due to the lack of internal membranes in prokaryotes with fast growth. ${ }^{15}$ High contents of unsaturated fatty acids, $50 \%$ of those with a carbon number less than $\mathrm{C}_{18}$, are typical of algal lipids and may need to be hydrogenated to improve their potential fuel properties. ${ }^{15}$ In the HTL conditions, TAGs are hydrolyzed to fatty acids and glycerol, which are not converted to an oil phase but rather to water-soluble soluble compounds in HTL. The free fatty acids are relatively stable, but partially degrade to produce long-chain hydrocarbons for transportation. ${ }^{44,87}$ Adding $\mathrm{NaOH}$ or $\mathrm{KOH}$ can increase the decomposition of fatty acids. ${ }^{44}$ In addition, hydrocarbons and lipids may be formed from small organic materials by Fisher-Tropsch reactions with water acting as the hydrogen source in the HTL conditions. ${ }^{44}$

\subsection{Effect of catalysts and HTL conditions on bio-crude oil properties and yields}

In general, HTL of microalgae is operated in a temperature range between 200 and $370{ }^{\circ} \mathrm{C}$, at pressures from 12 to $20 \mathrm{MPa}$, for 5 to $60 \mathrm{~min}$ in subcritical water with or without catalysts (alkaline or metal catalysts) under $\mathrm{CO}$ and $\mathrm{H}_{2}$ or inert gases, such as $\mathrm{N}_{2}$ and He. Selected HTL processes of microalgae with low to high lipid content, ${ }^{74,76-82}$ microalgae residues after extracting lipid or $\beta$-carotene, ${ }^{82,83}$ and macroalgae ${ }^{73,84,85}$ are summarized in Table 2. Table 2 lists the key parameters of temperature, time and catalyst used in HTL processes, the optimum conditions where maximum bio-oil yield was obtained, maximum bio-oil yields, and heating values. The table shows that feedstocks strongly affect bio-oil yield and properties, as optimum conditions are different for different feedstocks. Microalgae with high lipid content tend to generate a high oil yield. HTL also can convert low-lipid microalgae and its residues to bio-oil. Utilization of the low lipid algae may have potential for large-scale production, as well as potential environmental advantages because high-lipid algae usually have lower growth productivity compared to low-lipid algae. Algae that are 


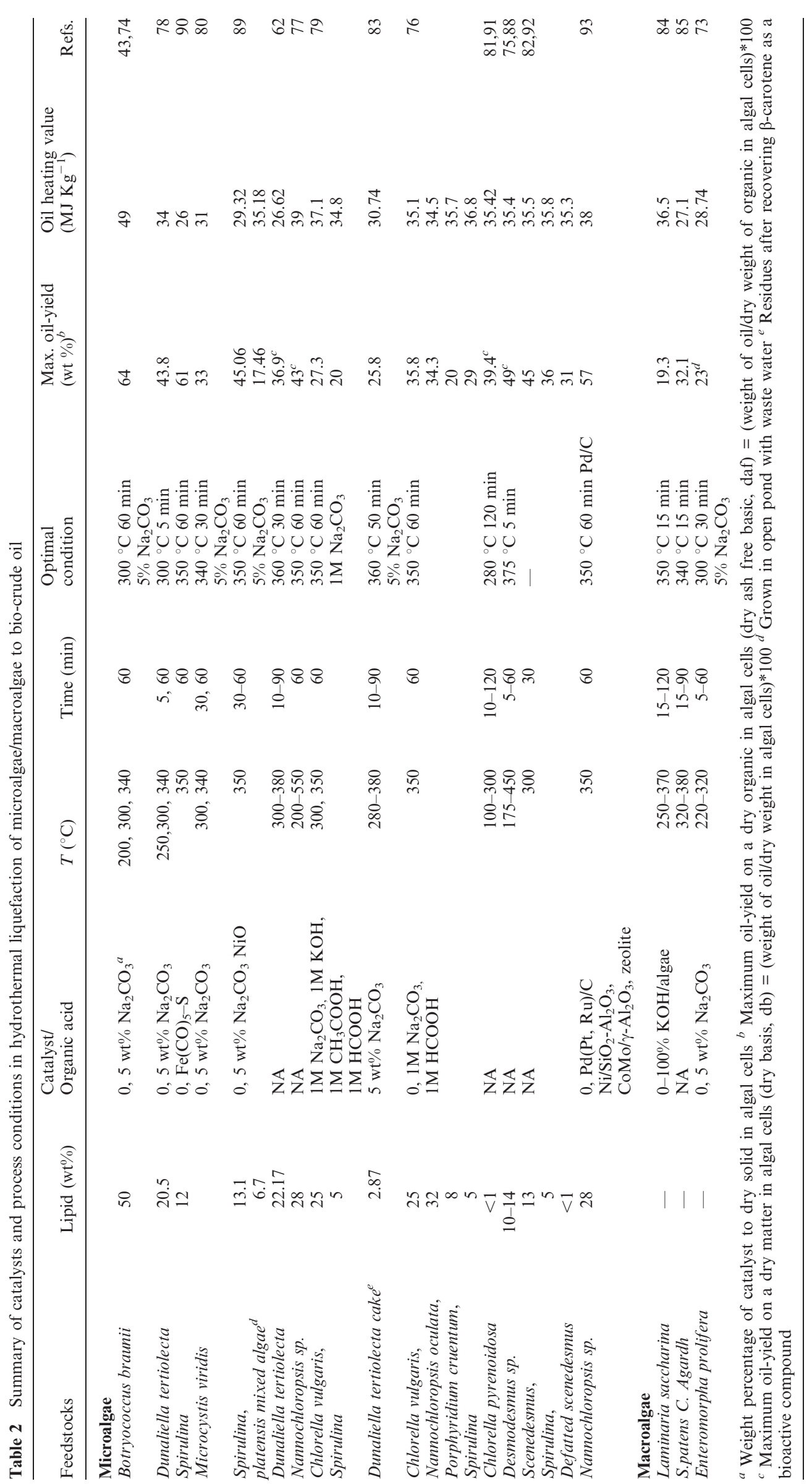


typically used for wastewater treatment, and also these species that form algal blooms in nature usually have low lipid contents. $^{75,81,82,89}$

The effect of catalyst loading along with temperature and reaction time on yield and properties of produced oil including viscosity and ultimate analysis were studied by Minowa et al. ${ }^{78}$ In their study, Dunaliella tertiolecta (microalgae) with $78.4 \%$ moisture content in common algae loading of about $10-20 \%{ }^{75,89}$ was converted in a $100 \mathrm{ml}$ autoclave. The process conditions were temperatures of 250,300 and $340{ }^{\circ} \mathrm{C}$, residence times of 5 and $60 \mathrm{~min}$ with high pressure (about $10 \mathrm{MPa}$ ), and $\mathrm{Na}_{2} \mathrm{CO}_{3}$ catalyst loadings of 0 and $5 \mathrm{wt} \%$ of the dry algae. The products of HTL included a bio-oil fraction (extracted by dichloromethane), a water soluble fraction, gases and solid residues. The oil yields on an organic basis were $31-44 \mathrm{wt} \%$ (average $37 \mathrm{wt} \%$ ), while the microalgae had $76.4 \mathrm{wt} \%$ dry basis non-ash organic content (daf). The oil obtained at $340{ }^{\circ} \mathrm{C}$ for $60 \mathrm{~min}$ had heating values of $36 \mathrm{MJ} \mathrm{kg}^{-1}$ and a viscosity of $150-330 \mathrm{mPa} \mathrm{s}$, which is comparable to fuel oil (about $40 \mathrm{MJ} \mathrm{kg}^{-1}, 50-1000 \mathrm{mPa} \mathrm{s}$ ). The gas yield was about $10 \%$ on an organic basis and the gas contained mainly $\mathrm{CO}_{2}$. The solid residue was negligible and the inorganic matter in the microalgae was mostly soluble in the aqueous phase. The catalyst, temperature, and reaction time affected the oil properties, but they did not significantly affect the oil yield. At the maximum oil yield obtained at $300{ }^{\circ} \mathrm{C}$ for $5 \mathrm{~min}$, the viscosity of the oil with the catalyst was $500 \mathrm{mPa} \mathrm{s}$ which is much lower than $14000 \mathrm{mPa}$ s without the catalyst. As the temperature increased, the viscosity of the oil decreased, its heating value increased slightly, the carbon and hydrogen contents increased and the oxygen content decreased. ${ }^{78}$ HTL of the Microcystis viridis strain was investigated using a similar method. ${ }^{80}$ The maximum oil yield was obtained at $340{ }^{\circ} \mathrm{C}$ for $30 \mathrm{~min}$ with $5 \mathrm{wt} \% \mathrm{Na}_{2} \mathrm{CO}_{3}$ and the oil had the maximum energy yield (the ratio of the weight of $\mathrm{C}$ and $\mathrm{H}$ in oil products after liquefaction to the weight of $\mathrm{C}$ and $\mathrm{H}$ in feedstock). ${ }^{80}$ In addition, the higher temperature increased both the oil yield and nitrogen content in the oil of Desmodesmus sp. ${ }^{75}$ and Chlorella pyrenoidosa. $^{81}$

Researchers also expanded the temperatures to $550{ }^{\circ} \mathrm{C}$ (above the water critical temperature of $374{ }^{\circ} \mathrm{C}$ ) to determine the effect on maximum oil yields. It was found that the maximum oil yields were obtained in the subcritical condition (Table 2). ${ }^{75,77,88}$ Brown et al. conducted tests using the microalgae Nannochloropsis at a processing temperature range of 200 to $500{ }^{\circ} \mathrm{C}$ and a reaction time of $60 \mathrm{~min} .{ }^{77}$ The highest bio-oil yield (dry basis) was $43 \mathrm{wt}^{\%} \%$ at $350{ }^{\circ} \mathrm{C}$ in subcritical water liquefaction. The oil yields decreased modestly from $400{ }^{\circ} \mathrm{C}$ to $450{ }^{\circ} \mathrm{C}$, and at $500{ }^{\circ} \mathrm{C}$ the yield was nearly half that achieved in supercritical water. In addition, the chemical composition of the oil and gas fractions changed with varying temperatures. The oils generated at lower temperatures consisted of fatty acids, alkenes, sterol-related compounds and heterocyclic N-containing compounds, with $\mathrm{CO}_{2}$ being the main compound in the gas phase. As the temperature increased, the oils showed more polycyclic aromatic hydrocarbons (PAHs), and the gas phase contained some lighter hydrocarbons (such as $\mathrm{CH}_{4}, \mathrm{C}_{2} \mathrm{H}_{4}$ and $\mathrm{C}_{2} \mathrm{H}_{6}$ ) in addition to $\mathrm{CO}_{2}$.

Recently, HTL research has moved toward providing a more detailed characterization of products, and determining the relationship between composition and HTL process conditions. ${ }^{75,80,88,92,94}$ The understanding of bio-oil chemical composition is required for improving the upgrading pathways for biooil to achieve higher quality products. Yang et al. ${ }^{80}$ studied HTL conditions for the Microcystis viridis strain using a method similar to that used by Monowa (Table 2). ${ }^{78}$ The liquefied oil was separated into four fractions using a thin layer chromatography and flame ionization detector (TLC-FID). ${ }^{80}$ The fractions included saturated compounds, aromatic compounds, resin and asphalt. Furthermore, a gas chromatography with mass spectrometer (GC-MS) was used to analyze low molecular weight saturated and aromatic hydrocarbon compounds. The saturated compounds in the oil were mainly n-alkanes of the $\mathrm{C}_{17}-\mathrm{C}_{18}$ hydrocarbon range, and the aromatic compounds contained n-naphthalene and n-dibenzothiophene, which are typical components in petroleum-based heavy oil. Therefore, the liquefied oil is similar to heavy oil. The gas consisted primarily of $\mathrm{CO}_{2}$ and methane. The solid residues decreased with increasing temperature and sodium carbonate addition. The aqueous phase had a total nitrogen concentration ranging from 998 to $1157 \mathrm{mg}$ $1^{-1}$ and a total phosphate concentration from 2.47 to $5.38 \mathrm{mg}$ $1^{-1}$. Half of the total nitrogen was detected as ammonia $\left(\mathrm{NH}_{3}-\right.$ $\mathrm{N})$. Therefore, authors suggested that the final process water will require further treatment to remove nitrogen and phosphate prior to disposal. On the other hand, microalgae growth requires nitrogen and phosphate. So, the nitrogen and phosphate in the water could potentially be recycled as nutrients for microalgae growth. ${ }^{75,81,95}$ At the same time, this approach would have an environment benefit. Microalgae grown in wastewater from secondary treated sewage or from the carpet industry was converted to bio-crude oil using HTL. ${ }^{43,89}$ Nitrogen distributions in the products of HTL of microalgae and macroalgae were evaluated for future nitrogen control and recycling studies. ${ }^{75,84}$

Ross et $a l^{79}$ investigated the effect of alkali catalysts and organic acids along with temperature on yield and properties of produced oil. The alkali included potassium hydroxide and sodium carbonate. The organic acids as hydrogen donors were acetic acid and formic acid. The microalgae Chlorella vulgaris, which was found to have a low lipid content and high protein content, was selected as the feedstock. The HTL was performed in a batch reactor at 300 and $350{ }^{\circ} \mathrm{C}$ for $1 \mathrm{~h}$. The oil yield based on organic content followed the trend $\mathrm{Na}_{2} \mathrm{CO}_{3}>\mathrm{CH}_{3} \mathrm{COOH}>$ $\mathrm{KOH}>\mathrm{HCOOH}$. The oil yield on a dry basis followed the trend $\mathrm{CH}_{3} \mathrm{COOH}>\mathrm{HCOOH}>\mathrm{KOH}>\mathrm{Na}_{2} \mathrm{CO}_{3}$. The bio-crude oils using the alkali catalysts had higher heating values, but the oils generated from HTL using organic acids had lower boiling points, as measured using thermal gravimetric analysis (TGA), and had better flow properties. The oils, analyzed using GC-MS, contained aromatic hydrocarbons, substituted phenols, nitrogen heterocycles, fatty acids and fatty acid amides. Elemental analysis of the algae oil showed that it had significantly lower oxygen content compared with the biomass pyrolysis oil. The overall elemental balance of nitrogen indicated that a large portion of the algae nitrogen (up to $50 \%$ ) is transferred to the aqueous phase in the form of ammonium $\left(\mathrm{NH}_{4}{ }^{-}\right)$. The nitrogen content of the oils typically was 4 to $6 \%$. Such high nitrogen content in the oil is undesirable because it increases $\mathrm{NO}_{x}$ emission as the fuel is combusted, and because of the technical challenges for upgrading bio-oil to remove nitrogen. ${ }^{75,82,84}$ 
Alkalis such as sodium carbonate have been widely used in the HTL of algae. Formates also have been found to have some amount of catalytic activity. ${ }^{64}$ The weak organic acids as hydrogen donors positively affect bio-crude oil yield and boiling point distribution of the oils, but may either decompose to gaseous products (such as $\mathrm{CO}$ and $\mathrm{H}_{2}$ ) or react with the microalgae degradation compounds in the HTL process. ${ }^{79}$ For considering homogeneous catalyst recovery and reuse issues following the HTL process, researchers applied metal catalysts to the HTL process (Table 2) as discussed in section 4.1. ${ }^{89,90,93}$ The catalysts affected the oil yield and oil properties. The HTL of Nannochloropsis sp. with $\mathrm{Pd} / \mathrm{C}$ had higher bio-crude oil yield and lower $\mathrm{O} / \mathrm{C}$ ratio in the oil than the oil from the uncatalyzed process. ${ }^{93}$ The metal catalyst function and catalytic mechanism are not clearly understood and more research is needed.

\subsection{Pathway of the hydrothermal liquefaction process}

The mechanisms for hydrothermal liquefaction reactions of microalgae to crude oil are not well understood. The proposed pathway is for the macromolecules of microalgae (lipids, proteins and carbohydrates) to first be hydrolyzed into small fragments (fatty acids, amino acids and glucose). Subsequently, the small fragments can be converted to smaller compounds, e.g. the amino acids undergo decarboxylation and deamination and produce mainly hydrocarbons, amines, aldehydes and acids. The generated compounds (intermediates) are unstable, and rearrange via condensation, cyclization and polymerization reactions to larger compounds. ${ }^{37,44,75,81,87}$ The complex interactions are not clearly understood and further study is needed. The properties of the product obtained depend on the components of the microalgae and the reaction conditions. An experimental study of the HTL of microalgae Desmodesus sp. at temperatures between 175 and $450{ }^{\circ} \mathrm{C}$ showed that hydrolysis dominates from $175{ }^{\circ} \mathrm{C}$ to $225-250{ }^{\circ} \mathrm{C}$, as shown by an increase in water-soluble organics, and low yields of oil were obtained. In the temperature range $250-375^{\circ} \mathrm{C}$, re-polymerization becomes predominant, with increasing oil yields and decreasing organic content in water. ${ }^{75}$

In the HTL of raw microalgae having an oxygen content of $31.7 \mathrm{wt}^{\mathrm{O}} \%$ on a dry organic basis, ${ }^{78}$ the oil derived from the microalgae had an oxygen content of 8.4 to $13.7 \mathrm{wt} \%$. Oxygen was removed during the HTL process in the form of water by dehydration or carbon dioxide by decarboxylation. ${ }^{44}$ The raw microalgae had an initial crude lipid content of $20.5 \mathrm{wt} \%$ on an organic basis, and produced $37 \mathrm{wt} \%$ of oil yield on an organic basis, which was higher than the microalgae crude lipid content. This means that not only lipids but also proteins and carbohydrates were converted to oil in the process. In addition, the maximum oil yield was $64 \%$ from HTL of the microalgae Botryococcus braunii while the microalgae starting material had crude lipid content of $50 \%{ }^{74}$ So, the higher the lipid content, the higher the bio-oil yield. Biller and Ross ${ }^{76}$ further confirmed this using model compounds of proteins (albumin, soya protein, and amino acids of asparagines and glutamine), carbohydrates (starch and glucose) and lipids (triglyceride from sunflower oil) and microalgae strains with high (Chlorella vulgaris, Nannochloropsis occulata) and low (Porphyridium cruentum and the cyanobacteria Spirulina) lipid contents. Fig. 4 shows the yields of products of the model compounds and microalgae based on a dry, ash-free basis in sodium carbonate at $350{ }^{\circ} \mathrm{C}$ for $60 \mathrm{~min}$.

\section{®Aqueous Phase $\$$ Gas $\square$ Solid residue Bio-crude}

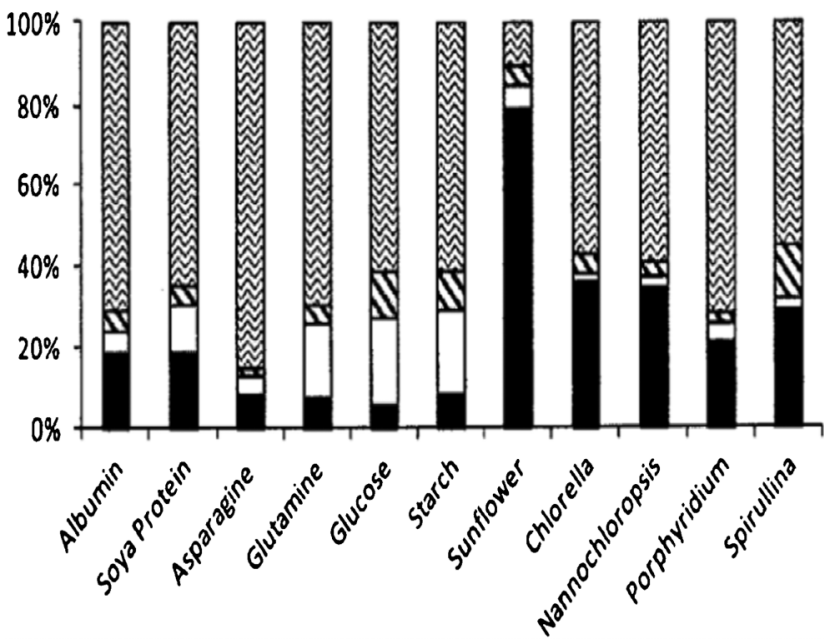

Fig. 4 Yields of products from hydrothermal processing of microalgae and model compounds at $350{ }^{\circ} \mathrm{C}$ for $60 \mathrm{~min}^{76}$

Bio-crude oil was generated from each biochemical component. This is a unique advantage of HTL compared with conventional lipid extraction and conversion methods, and speaks to the conversion efficiencies and yields that are possible with the HTL process. Furthermore, the results of studies using model compounds and microalgae oil also showed that the relative oil contributions were lipids $>$ proteins $>$ carbohydrates.

Water plays an important role in the HTL processes. It serves as a solvent (vehicle) for the reactions, supplies hydrogen for addition to the substrate, and hydrolyzes high molecular weight reactants such as carbohydrates and proteins. ${ }^{44,64}$ As the water temperature increases, for example from $25{ }^{\circ} \mathrm{C}$ to $300{ }^{\circ} \mathrm{C}$, the relative permittivity decreases from 78.85 to 19.66 , indicating that ordinarily very polar water molecules become relatively non-polar, which allows the water to show greater affinity for the non-polar organic hydrocarbons. ${ }^{68}$ In addition, the dissociation of water dramatically increases with the increase of temperature. For example, the water dissociation constant at $300{ }^{\circ} \mathrm{C}$ is about 500 times higher than that at $25{ }^{\circ} \mathrm{C}$, under atmospheric pressure. ${ }^{68}$ Water is split into $\mathrm{H}^{+}$and $\mathrm{OH}^{-}$ions via hydrolysis or dissociation, which is reversible and rapid. In that way, the rate of both acid- and base-catalyzed reactions is increased.

\section{Transesterification of algae feedstocks}

Traditional biodiesel fuels, i.e., FAMEs, produced from various biomass feedstocks via transesterification reactions are commercially avaliable. ${ }^{36,37,40-42}$ Although the technique of transesterification has been around for over a century, it has only recently been used for obtaining fuel from algae oil. Transesterification of extracted algal lipids is another fuel production pathway, in addition to thermochemical conversion of the entire algal mass, such as via HTL as described previously.

\subsection{Transesterification}

Many microalgae species can be induced to produce and accumulate substantial amounts of lipids (such as fatty acids 
and glycerides). Under certain conditions, lipid content in some species can reach up to $90 \%$ of dry weight. ${ }^{21,42}$ Beal et al. ${ }^{96}$ laid out a framework to report the production of renewable diesel from algae and analyzed several production pathways. Usually, triglycerides (TG) in algal lipids can be converted to traditional biodiesel (mixture of FAMEs) through the transesterification process. A general overview of the transesterification reaction of TG with methanol is

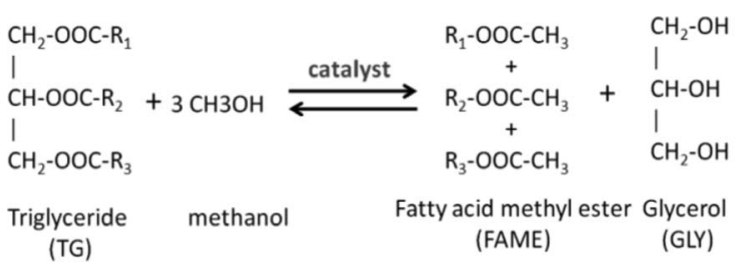

in which one triglyceride and three alcohols (methanol) form three FAMEs and one by-product glycerol (GLY), in the presence of a catalyst. ${ }^{42,97-101}$ In the literature, computational modelling of transesterification focuses on the kinetics and the mechanism of the reactions and product design. ${ }^{102}$ Freedman et $a{ }^{98}{ }^{98}$ proposed a three-step reaction scheme for the overall transesterification reaction (1) that includes the reaction intermediates, monoglyceride (MG) and diglyceride (DG), as shown in the following:

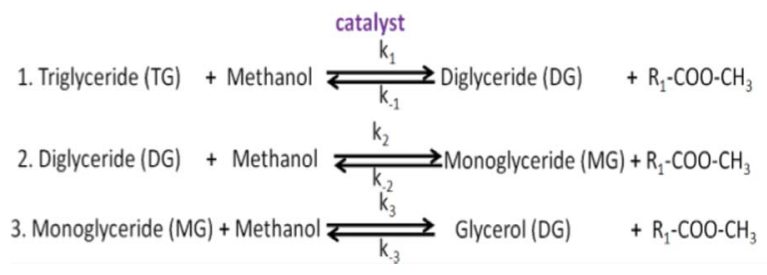

First, the carbonyl carbon of the triglyceride molecule reacts with the alkoxide ion to form a tetrahedral intermediate. Then, this intermediate reacts with an alcohol to produce an alkoxide ion. Finally, the tetrahedral intermediate rearranges into an ester and a diglyceride. Similarly, this transesterification mechanism can be extended to di- and mono-glyceride intermediates. By examining the effects of the molar ratio of methanol to soybean oil, the type and amount of catalyst and the reaction temperature on rate constants and kinetic order, they found that the forward reactions appear to be pseudo-first order or second order depending upon conditions used, while the reverse reactions appear to be second order. ${ }^{103}$ Based on batch and loop reactor modelling, Tesser et al. ${ }^{101}$ simulated the FFAs esterification and found that with a packed bed loop reactor configuration with multi-steps operation, high FFA conversion can be obtained, and the methanol-water separation costs could be reduced by lowering the methanol/acid ratio.

Such transesterification reactions can be base-catalyzed, acidcatalyzed and enzyme-catalyzed. Traditional homogeneous catalysts, such as $\mathrm{KOH}, \mathrm{NaOH}$ and $\mathrm{H}_{2} \mathrm{SO}_{4}$, have been reported for direct transesterification of algae oil to biodiesel. ${ }^{25,104,105}$ Usually, base-catalyzed transesterification requires shorter reaction times and lower temperatures, while acid-catalyzed transesterification requires more time as well as elevated temperatures to complete. ${ }^{106}$ For example, Freedman et al. ${ }^{106}$ reported that, when using the base catalyst $\mathrm{NaOH}$, the transesterification of vegetable oil was $99 \%$ complete at $32{ }^{\circ} \mathrm{C}$ in $4 \mathrm{~h}$, whereas at $60{ }^{\circ} \mathrm{C}$ the reaction was complete in one hour. Compared with the alkali catalyst, they also observed that the transesterification by acid catalyst was much slower. However, solid acid catalysts can carry out transesterification and esterification simultaneously using low-cost feedstocks, without multiple reaction and posttreatment steps, greatly improving the economics of biodiesel production. ${ }^{107}$ Because algal biomass contains lipids and other chemicals, a pre-treatment process, i.e., extraction, is typically involved before the transesterification reactions. D'Oca et al. 108,109 investigated the extraction of lipids from the dry biomass of Chlorella pyrenoidosa and compared the transesterification of lipidic extracts with direct transesterification of dry biomass. They found that extraction with methanol followed by the transesterification process resulted in a higher FAMEs yield from biomass than the direct transesterification process using methanol. Miao and $\mathrm{Wu}^{110}$ reported the acidic transesterification of the extracted algae oil from Chlorella protothecoides using n-hexane as extraction solvent. The optimized operating conditions were reported as $56: 1$ molar ratio of methanol to oil at a temperature of $30{ }^{\circ} \mathrm{C}$, with a reaction time of $4 \mathrm{~h}$.

It is difficult to extract algae oil from their tough, rigid cell wall structures using conventional mechanical pressing and subsequent solvent extraction methods. Microwaves can directly penetrate through these cell walls to assist the oil extraction. Recently, a new microwave assisted process ${ }^{111}$ has been reported to simultaneously extract algae oil and transesterify it to FAME. A schematic of the microwave-assisted extractive-transesterification $^{111}$ process to transform algal biomass (Inoculum Nannochloropsis sp.) to biodiesel is shown in Fig. 5. Wet algal biomass was first pre-dried in a vacuum oven at $50-60{ }^{\circ} \mathrm{C}$ overnight and was ground under liquid $\mathrm{N}_{2}$ conditions. The dry algal powder thus obtained was added to the premixed homogeneous solution of methanol and $\mathrm{KOH}$ catalyst to produce biodiesel. The FAME yield for this microwave-assisted simultaneous extraction and transesterification reaction process was greater than $70 \%$ at optimal conditions, having a dry algae to methanol (wt/vol) ratio of around $1: 12$, a $\mathrm{KOH}$ concentration of $2 \mathrm{wt} . \%$ and a reaction time of $4 \mathrm{~min}$, at a reaction temperature of around $60-64{ }^{\circ} \mathrm{C}$. The mechanism of base-catalyzed microwave transesterification is similar to traditional transesterification of vegetable oil ${ }^{98}$. It was also reported ${ }^{112}$ that the microwave assisted process could shorten FAME recovery time from reaction mixtures.

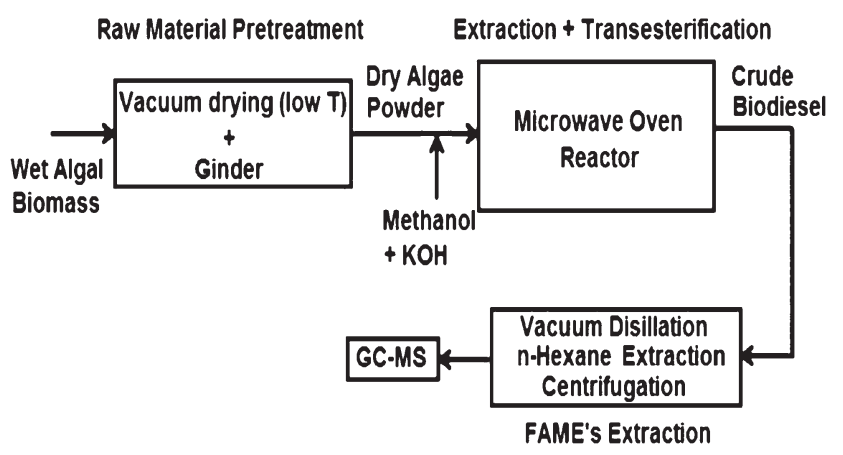

Fig. 5 Single-step microwave transesterification process for dry algal biomass. Modified from Ref. 111 
Direct conversion ${ }^{111,113-116}$ of algal biomass to bio-diesel is of high interest to researchers because of the economic and energy advantages of by-passing the time-intensive extraction and clean up steps. Direct transesterification enhanced by a solvent extraction process was recently reported ${ }^{113}$ for the production of biodiesel from the algae Schizochytrium limacinum, as shown in Fig. 6. Under similar reaction conditions, using sulfuric acid at $90{ }^{\circ} \mathrm{C}$ for $40 \mathrm{~min}$, direct transesterification of algae biomass resulted in a higher biodiesel yield and FAME content than the traditional two-step extraction-transesterification method. The sulfur content was also higher than the ASTM required level, probably due to the use of $\mathrm{MgSO}_{4}$ in the algal culture media. A one-step supercritical methanol transesterification process was reported ${ }^{116}$ for direct liquefaction and conversion of a wet algal biomass (Inoculum Nanno-chloropsis sp.), containing about 90\% water, to biodiesel. The reaction conditions are milder than those required for pyrolysis and prevent the formation of by-products. More than $80 \%$ FAME yield can be reached under the optimal conditions, given as a wet algae to methanol ratio (wt/vol) of around $1: 9$, with a reaction pressure, temperature, and time of about $1200 \mathrm{psi}, 255^{\circ} \mathrm{C}$ and $25 \mathrm{~min}$ respectively.

Normally, these homogeneous transesterifications are performed in a batch operation. But because the catalysts are soluble in both reaction products, FAME and glycerol phases, after the reaction, the resulting biodiesel needs to be neutralized, washed with water, and then dried. The complicated posttreatment process and the huge amount of produced wastewater limit the homogeneous catalytic transesterification process. Because heterogeneous catalysts can be easily separated from the reaction mixture and regenerated through many cycles, the development of a continuous reaction system based on a heterogeneous catalyst can greatly reduce the process and catalyst consumption costs. Many attempts have been made to
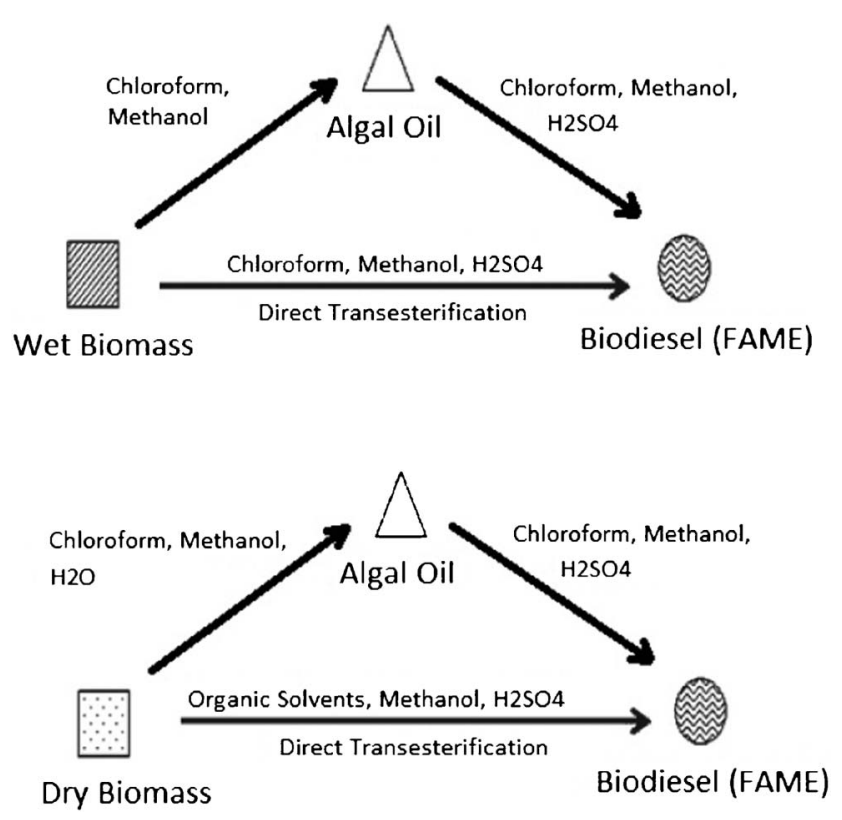

Fig. 6 Methods used in the preparation of biodiesel from algal biomass: extraction-transesterification and direct transesterification. Modified from Ref. 113. develop a heterogeneous catalyst with high tolerance to FFA and water in the feedstock.

Base heterogeneous catalysts, including alkaline earth metal oxides, zeolites and mixed oxides, have been widely used in biofuels production. ${ }^{117} \mathrm{~A}$ modified $\mathrm{ZnO}$ catalyst $\left(\mathrm{Zn}_{3} \mathrm{La}_{1}\right)$ was used in the heterogeneous transesterification ${ }^{118}$ of crude algae oil with an additional $3 \%$ water and 5\% FFA at $200{ }^{\circ} \mathrm{C}, 500$ psi, and a methanol/oil ratio of $14: 1-26: 1$ (mol/mol). The FAME yield was around $70 \%$. In $\mathrm{Zn}_{3} \mathrm{La}_{1}$, lanthanum partially replaced zinc atoms in $\mathrm{ZnO}$ crystals, which weakened the neighbouring oxygen bonds, making them more reactive. In addition, the wurtzite $\mathrm{ZnO}$ crystal structure doped with $\mathrm{La}$ was stable under the reaction conditions, as verified by the similar XRD patterns for both fresh and spent catalysts.

Mixed metal oxides, $\mathrm{Al}_{2} \mathrm{O}_{3}$-supported $\mathrm{CaO}$ and $\mathrm{MgO}$ catalysts, have been investigated in the transesterification of lipid from the microalgae, Nannochloropsis oculata. ${ }^{119}$ Although $\mathrm{CaO}$ and $\mathrm{MgO}$ were solid basics, no transesterification activity was obvious for the microalgal lipid under the reaction conditions of $50{ }^{\circ} \mathrm{C}$ and a methanol/lipid molar ratio of 30. The support catalyst, i.e., $80 \% \mathrm{CaO} / \mathrm{Al}_{2} \mathrm{O}_{3}$, showed a very high biodiesel yield, over $97 \%$, under these reaction conditions. Rather than the crystallite sizes of these alkaline earth metal oxides, the basic site density and basic strength played significant roles in the biodiesel yield. $\mathrm{Mg}-\mathrm{Zr}$ solid base catalyst ${ }^{120}$ was used in the one-step transesterification of the green microalgae Nannochloropsis sp. at $65{ }^{\circ} \mathrm{C}$. Compared to the biodiesel yield via the conventional extraction-transesterification method $(22.2 \%)$, with a $10 \% \mathrm{Mg}-$ $\mathrm{Zr}$ catalyst and a mixed solvent (methanol/methylene dichloride $=2: 1, \mathrm{v} / \mathrm{v}$ ) under the same reaction temperature of $65^{\circ} \mathrm{C}$ for $4 \mathrm{~h}$, the one-step method could give a higher yield of methyl ester $(28.0 \%)$. Moreover, the solid catalyst could be easily separated from the microalgae residue, which could eventually reduce operating units as well as overall costs.

Hydroxide-modified Ti catalysts ${ }^{121,122}$ have been used for continuous catalyzed transesterifications of algae oil from species Dunaliella tertiolecta and Inoculum Nanno-chloropsis sp for fast production of biodiesel at elevated temperature and pressure. About 90\% FAMEs yield was achieved within $60 \mathrm{~s}$ at $340-350{ }^{\circ} \mathrm{C}$, and 3650 psi, or about $85 \%$ FAMEs yield within $30 \mathrm{~s}$ under supercritical methanol conditions, i.e., $340{ }^{\circ} \mathrm{C}$ and 2250 psi, with an algae lipids : methanol : hexane ratio of $1: 3: 96$.

\subsection{Saponification and hydrolysis}

Typically, homogeneous catalysts are sensitive to water and FFAs in the feedstock. Compared to other catalytic reactions, reactants for transesterification must be free of water because in the presence of water, triglycerides hydrolyze and form the salts of the fatty acids and then transesterification stops. FFAs react with basic catalysts $(\mathrm{NaOH}$ and $\mathrm{KOH})$ and form soaps, as shown in the following reactions:

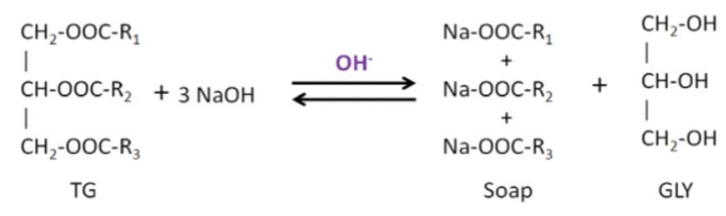




$$
\begin{gathered}
\mathrm{R}-\mathrm{COOH}+\mathrm{NaOH} \longrightarrow \mathrm{H}_{2} \mathrm{O}+\mathrm{R}-\mathrm{COO}-\mathrm{Na} \\
\text { Free Fatty Acid } \\
\text { Soap }
\end{gathered}
$$

This complicates the glycerol separation and drastically reduces the methyl ester yield.

The saponification leads to lower production of biodiesel and a higher cost for the required purification process. Based on the work done by Freedman et al. ${ }^{98,106}$ Komers et al. ${ }^{99}$ explored the kinetics and mechanism of the $\mathrm{KOH}$-catalyzed methanolysis of rapeseed oil for biodiesel production using a model consisting of two sequences of consecutively competitive reactions (methanolysis and saponification). Their modelling results could accurately describe real cases with a probability of about $78 \%$ at given conditions. This model showed that all reaction rates were proportional to the amount of catalyst, which varies over time and is consumed in the competing saponification reactions. For base-catalyzed reactions, if the starting lipid contains more than $0.5 \mathrm{wt} \%$ of FFAs, a preliminary stage of acidity reduction is necessary by means of an esterification reaction of the FFAs, to avoid their saponification. Tesser et al. ${ }^{100}$ explored the kinetics of fatty acid esterification on acid exchange resins. As catalysts, the active site in acid ionic exchange resins is the sulfuric group, which exchanges its hydrogen ion with the components involved in the reaction after they are adsorbed on the resin surface. Their results showed that the rate-determining step is the surface reaction of protonated fatty acid with methanol that leads to the formation of a protonated methyl ester. This model can provide a good description of the kinetic behaviour, in particular for reactions performed at different catalyst concentrations. Meanwhile, in order to minimize problems associated with the homogeneous catalytic process, such as removal of catalyst after reaction, soap formation minimization, corrosion, and environmental issues, heterogeneous solid catalyst systems are favoured. For example, Kim et al. ${ }^{123}$ found that strongly basic anionexchange resins could be used as a heterogeneous catalyst exhibiting synergetic effects for the transesterification reactions.

Hydrolysis and transesterification are two competing reactions that can occur during the synthesis of biodiesel, in which the catalysts play important roles. ${ }^{121}$ Cheirsilp et al. ${ }^{97}$ developed three kinetic models of the transesterification of palm oil fatty acids to ethanol using an immobilized lipase catalyst. Their results showed that the rate constants for alcoholysis of palm oil with ethanol are much higher than those for the hydrolysis reaction. The simulated results also showed that increasing the initial ethanol concentration increases the initial production rate and yield of fatty acid ethyl ester and lowers the final concentration of free fatty acid. Using a tungstated zirconia catalyst, Ngaosuwan et al. ${ }^{107}$ investigated the mechanistic pathways for hydrolysis (with water) and transesterification (with methanol) of tricaprylin and found that increasing the concentration of tricaprylin increased the reaction rates for both hydrolysis and transesterification under all conditions. However, water inhibited the reaction rate of hydrolysis by poisoning the active sites. With a low water-to-tricaprylin ratio, the ratedetermining step for hydrolysis is the adsorption of tricaprylin, while the rate-determining step for transesterification is the surface reaction at a low methanol-to-tricaprylin ratio. Based on quantum mechanical calculations, Zhang et al. ${ }^{124}$ investigated the mechanisms of the conversion of methyl lactate (ML) over sodium tripolyphosphate. Their calculated results indicated that the conversion of ML over a catalyst is mainly through the direct decomposition of ML to methyl acrylate and methanol, and also through the decarbonylation of ML to acetaldehyde, methanol and $\mathrm{CO}$ via stepwise mechanisms. Based on ab initio quantum chemistry calculations, Turner et al. ${ }^{125,126}$ investigated the alkaline hydrolysis of esters with methyl acetate and methyl benzoate model systems. From the calculated reaction pathway for the first step in the alkaline hydrolysis of esters, they identified one transition state and one intermediate product.

Except for the catalytic hydrotreating or transesterification of TG to hydrocarbons as described above, the thermal cleavage of TG is another pathway with a unique feature to form cyclic hydrocarbons. Instead of via a Diels-Alder reaction, based on the experimental evidence, Kubatova et al. ${ }^{127}$ proposed that the cyclic hydrocarbons are produced through intramolecular radical cyclization. In general, although varying by engine type, ignition characteristics and specific compression ratios, the presence of 5-20 $\mathrm{wt}^{\%} \%$ cyclic hydrocarbons (including aromatics) in transportation fuels can improve the operational performance. Therefore, such attempts are meaningful and further discovery is highly desired. ${ }^{127}$

\subsection{Glycerol reforming}

As described in the previous sections (eqn (2)) glycerol (GLY) is a by-product formed in biodiesel production, and new efficient procedures for its transformation into valuable derivatives, such as via hydrodeoxygenation, are in high demand. ${ }^{4,128-132}$ Some promising derivatives include dihydroxyacetone (DHA), glyceric acid (GLS) and $\mathrm{H}_{2}$. Fig. 7(a) demonstrates a reaction network of $\mathrm{Pt}-\mathrm{Bi} / \mathrm{C}$-catalyzed glycerol oxidation proposed by Wörz et al. ${ }^{130}$ The figure shows that the main products could be GLA, GLS and DHA. MOS, HBTS, and TS (their molecular structures are defined in Fig. 7(a)) are chelating agents and not the main

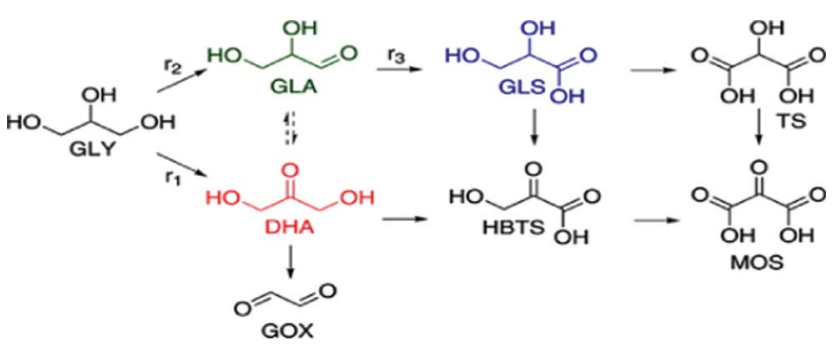

(a)

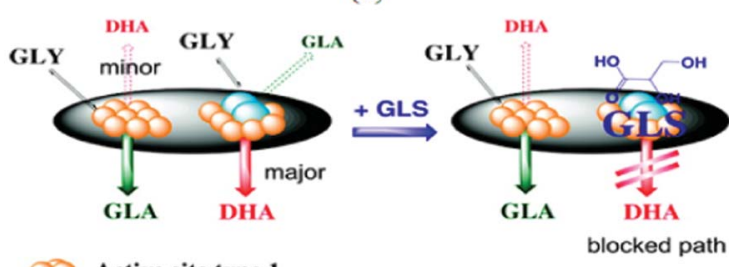

Active site type 1

Active site type 2

(b)

Fig. 7 (a) Typical reaction network of Pt-Bi/C-catalyzed glycerol oxidation. (b) Proposed mechanism of selective deactivation induced by glyceric acid. ${ }^{130}$ 
products from their results. One major problem for technical realization is the deactivation of the catalyst, especially in acidic media. Based on kinetic modelling as shown by the schematic in Fig. 7(b), the produced GLS easily adsorbs on the catalyst active sites and therefore reduces both the conversion of glycerol and the selectivity toward DHA. Therefore, to increase the DHA yield and glycerol conversion, developing new methods of separating glyceric acid in situ from the reaction mixture is critical. With a $\mathrm{ZrO}_{2}-\mathrm{FeO}_{\mathrm{x}}$ catalyst, Yoshikawa et al. ${ }^{133}$ used an aqueous glycerol solution as a feedstock in a fixed-bed flow reactor at $623 \mathrm{~K}$ under atmospheric pressure to produce useful chemicals. Their products include propylene, allyl alcohol, carboxylic acids and ketones.

Another method for glycerol reforming is to produce renewable $\mathrm{H}_{2}$ and $\mathrm{CO}_{2}$ through the steam reforming process: $\mathrm{C}_{3} \mathrm{H}_{8} \mathrm{O}_{3}+3 \mathrm{H}_{2} \mathrm{O} \rightarrow 7 \mathrm{H}_{2}+3 \mathrm{CO}_{2}{ }^{128,129}$ Employing a COMSOL Multiphysics modelling package, Adhikari et al. ${ }^{128}$ explored the kinetics and reactor modelling of the glycerol steam reforming process over a $\mathrm{Ni}$-based $\mathrm{CeO}_{2}$-supported catalyst. Based on a power model, the simulated activation energy and the reaction order for the above reaction were found to be $103.4 \mathrm{~kJ}$ $\mathrm{mol}^{-1}$ and 0.233 , respectively. Wawrzetz et al. ${ }^{129}$ measured the rate for the formation of gaseous products from $30 \mathrm{wt} \%$ glycerol at $T=498 \mathrm{~K}$ and total pressure $=29 \mathrm{bar}$, with a $3 \mathrm{wt} \% \mathrm{Pt} / \mathrm{Al}_{2} \mathrm{O}_{3}$ catalyst, and found that the main products are $\mathrm{H}_{2}$ (with a rate of $\left.3.53 \mathrm{~min}^{-1}\right)$ and $\mathrm{CO}_{2}\left(2.32 \mathrm{~min}^{-1}\right)$, with other minor products being $\mathrm{CH}_{4}\left(0.079 \mathrm{~min}^{-1}\right), \mathrm{C}_{2} \mathrm{H}_{6}\left(0.040 \mathrm{~min}^{-1}\right), \mathrm{C}_{3} \mathrm{H}_{8}(0.012$ $\left.\min ^{-1}\right)$, and $\mathrm{CO}\left(0.003 \mathrm{~min}^{-1}\right)$. By photofermentation under optimal conditions, the reformation of biodiesel-derived crude glycerol to hydrogen could reach as high as 6.1-6.96 mol hydrogen/mole of crude glycerol, a yield of $96 \%$ of the theoretical maximum. ${ }^{134,135}$ Recent studies showed that by adding $\mathrm{CaO}$ into the reaction system for enhanced steam reforming, a high purity of hydrogen can be achieved from a single-reactor process. ${ }^{131}$ The esterification of glycerol with acetic acid was carried out over different solid acid catalysts in a slurry reactor by Zhou et al. ${ }^{136}$ Their results showed that at optimal operating conditions (molar ratio of acetic acid to glycerol $=9: 1$ at $110{ }^{\circ} \mathrm{C}$ ), the predicted glycerol conversion could reach $98.47 \%$.

The biological conversion of crude glycerol into high-value biochemicals may be one of the most promising alternatives available. Nitayavardhana and $\mathrm{Khanal}^{137}$ examined the potential for producing an edible fungus (animal feed) from biodieselderived crude glycerol. Such an alternative approach for glycerol utilization could provide a unique sustainable option for biodiesel refineries and an additional source of revenue from reaction products.

\section{Heterogeneous catalytic conversion of microalgal lipids to liquid fuels}

Most of the current technologies to convert microalgae-based feedstocks are still in their early stages. ${ }^{138}$ Due to undesirable oxygen groups in FAMEs, these conventional biodiesels suffer from high water content and poor low-temperature properties and are susceptible to microbial fouling. ${ }^{31,47,48}$ Besides, a large quantity of glycerol produced from FAMEs manufacturing is being considered a waste material. Therefore, catalytic hetero- geneous conversions, including hydrothermal liquefaction, hydrocracking, hydrodeoxygenation and decarboxylation, of microalgae-based feedstocks, i.e. bio-crude and lipids, to transportation fuels have attracted lots of attention. While the use of commercial hydro-processing technology ${ }^{139-141}$ for the production of transportation fuels is less of a challenge in terms of material development and reactor design, it consumes a large amount of $\mathrm{H}_{2}$ at operating conditions. The catalytic deoxygenation of FFAs (the model compounds most often studied as surrogates for lipid-rich microalgae) to diesel-range hydrocarbons over heterogeneous catalysts has attracted much attention because it requires little or no $\mathrm{H}_{2}$ consumption. However, this process requires further understanding of the catalyst function and catalytic mechanism. In this section, we summarize the current progress on the conversion of microalgae to transportation fuels.

\subsection{Heterogeneous hydrothermal liquefaction of algae feedstock}

Heterogeneous hydrothermal liquefaction of microalgae has recently been investigated by many researchers. Typically, the bio-oil yields were in a range of $24-45 \mathrm{wt} \%$. However, bio-oil physico-chemical characteristics, including heating values and distribution of components, were highly influenced by conversion method and feedstock. ${ }^{89,90,93,142}$ The use of heterogeneous catalysts during HTL of microalgae was recently reported to produce higher quality bio-oil by lowering the oxygen content in products.

Early in 1997, Matsui et al. ${ }^{90}$ investigated the liquefaction of micro-algae (spirulina) with an iron catalyst $\left(\mathrm{Fe}(\mathrm{CO})_{5}-\mathrm{S}\right)$ and obtained $66.9 \mathrm{wt} \%$ oil yield at $350{ }^{\circ} \mathrm{C}$ for $60 \mathrm{~min}$ in tetralin. Fig. 8 shows the effect of $\mathrm{Fe}(\mathrm{CO})_{5}-\mathrm{S}$ catalyst level on the product distribution. The oil yields increased linearly from 54.4 to $63.7 \mathrm{wt} \%$ as the amount of catalyst increased from 0 to $1.0 \mathrm{mmol}$, but the conversion and gas yield were nearly constant. They also found that liquefaction in toluene gave oil fractions of high carbon content and lower oxygen content, while liquefaction in water had a lower carbon content and a higher oxygen content

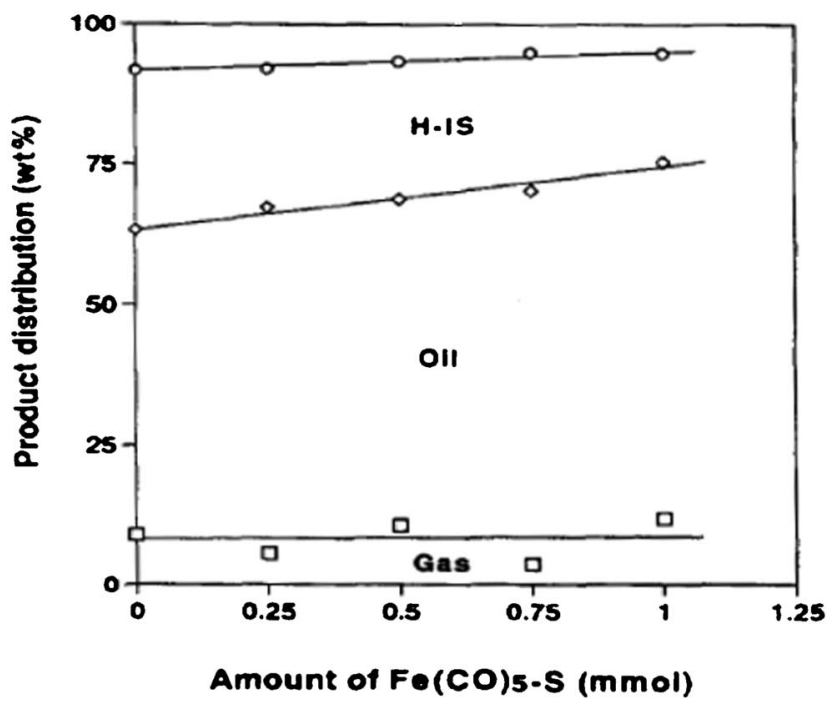

Fig. 8 Effect of catalyst level on product distribution in liquefaction of Spirulina in 1-methylnaphthalene under hydrogen at $350{ }^{\circ} \mathrm{C}$ for $60 \mathrm{~min} .{ }^{90}$ 
with an oil yield of $61 \mathrm{wt} \%$ at $350{ }^{\circ} \mathrm{C}$ as shown in Table 2 . The presence of $\mathrm{Ni} / \mathrm{Al}_{2} \mathrm{O}_{3}$ catalysts was found ${ }^{142}$ to convert the triglycerides to fatty acids then to alkanes at $350{ }^{\circ} \mathrm{C}$, at pressures of 150-200 bar in water, and the de-oxygenation of bio-crude increased by up to $10 \%$. At near-supercritical and supercritical conditions, the addition of water could enhance the mixing of reactants and therefore speed up the reactions. Water could also serve as solvent, and reactant. ${ }^{143-145} \mathrm{Fu}$ et al. ${ }^{146,147}$ also reported the deoxygenation of model algae fatty acids to linear hydrocarbons in near-supercritical or supercritical water. Activated carbons, metal salts and high-surface-area supported metal catalysts were investigated for activity toward deoxygenation of palmitic acid. Reaction temperatures ranged from 290 (nearcritical water) to $380{ }^{\circ} \mathrm{C}$ (supercritical water), and the pressure was the saturated or supercritical pressure of water at reaction temperatures, for example, 280 bar at $380{ }^{\circ} \mathrm{C}$. On activated carbon, $5 \%$ platinum and $5 \%$ palladium were effective for hydrothermal deoxygenation of palmitic acid, with more than $90 \%$ selectivity toward pentadecane. ${ }^{146}$ Also for the first time activated carbons were shown to convert saturated and unsaturated fatty acids to fuel-range hydrocarbons in a hydrothermal environment. ${ }^{147}$ This approach has important practical value for the energy industry by offering a low-cost approach to convert triglyceride-derived fatty acids into hydrocarbons, eliminating the need for expensive precious metal catalysts. The kinetic study suggested that the reaction was firstorder for palmitic acid over $\mathrm{Pt} / \mathrm{C}^{146}$ and activated carbons, ${ }^{147}$ with a calculated Arrhenius activation energies of $79 \mathrm{~kJ} \mathrm{~mol}^{-1}$, and $125 \mathrm{~kJ} \mathrm{~mol}^{-1}$, respectively. Nevertheless, these results shed new light on the role of activated carbons in bio-fuel production. A preliminary regenerability study indicated that no significant activity loss occurred for regenerated catalysts.

Possible pathways for the deoxygenation of stearic acid over heterogeneous catalysts at supercritical water conditions was investigated. ${ }^{148}$ In a batch reactor at $673 \mathrm{~K}$, by adding basic catalysts, such as alkali hydroxide $(\mathrm{NaOH}$ and $\mathrm{KOH})$, the monomolecular decarboxylation of stearic acid produced $\mathrm{CO}_{2}$ and $\mathrm{C} 17$ alkane. Different bimolecular decarboxylation pathways were proposed over metal oxide catalysts $\left(\mathrm{CeO}_{2}, \mathrm{Y}_{2} \mathrm{O}_{3}\right.$ and $\mathrm{ZrO}_{2}$ ), as shown in Fig. 9. The resultant $\mathrm{C} 16$ alkene may be produced via the direct bimolecular decarboxylation of stearic acid, or via the decomposition of intermediate C35 ketone, and/ or 2-nonadecanone, which were found in the products as well.

\subsection{Hydroprocessing of bio-crude oils}

The chain-lengths of the hydrocarbons obtained from biological feedstocks are typically $\mathrm{C} 11$ and above (typically, C14-C22). In order to produce light hydrocarbons (such as the jet fuel JP-8) from heavy hydrocarbons, hydrocracking and hydroisomerization processes are necessary.

Currently, hydrocracking is commonly practiced in the petroleum refinery industry to treat oil residua. Most frequently used hydrocracking catalysts for bio-crude oils were precious metal based catalysts, including $\mathrm{Co}$ and $\mathrm{Ru}$, and zeolites. Hillen and coworkers ${ }^{140,141}$ reported the hydrocracking of botryococcus extracts using cobalt-molybdenum catalysts at temperatures of $400-440{ }^{\circ} \mathrm{C}$. The resulting products consisted of more than $80 \%$ of low molecular weight, linear alkanes and isomers, which were

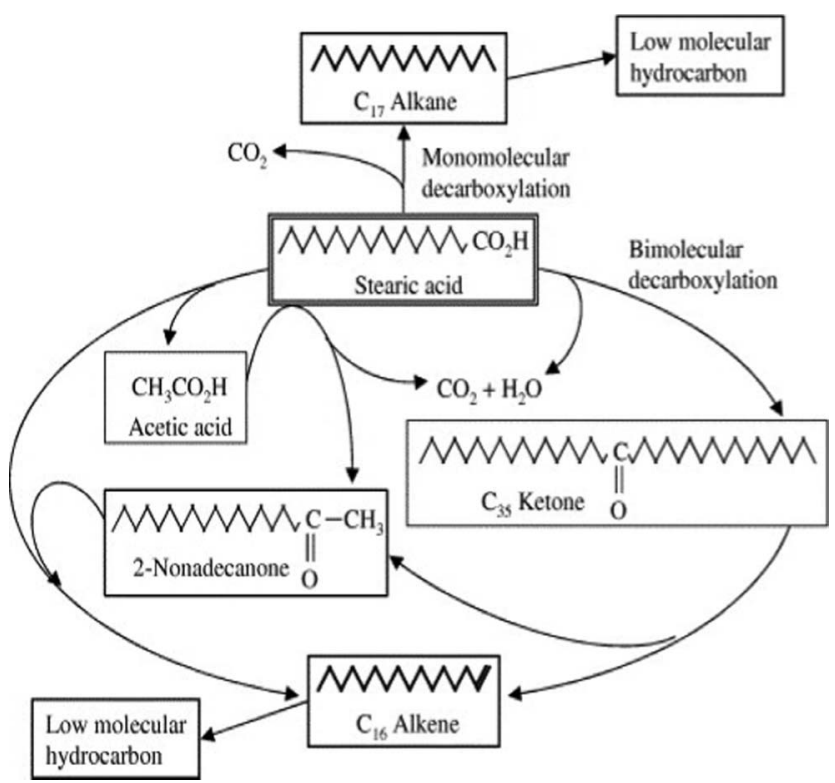

Fig. 9 Pathways for stearic acid conversion in supercritical water with and without additives. ${ }^{148}$

in the gasoline and jet fuels range. About $15 \%$ of the cracking products were classified in the diesel fraction. Kitazato et al. ${ }^{149}$ studied aromatic hydrocarbons produced from the cracking of botryococcenes using H-zeolite as the catalysts. The proposed mechanism involved pathways of consecutive cracking of botryococcenes with subsequent aromatization, as shown in Fig. 10. The potential cracking sites were between a carbon with a methyl group and a carbon with an unsaturated double bond. However, Sharma and Bakhshi ${ }^{150}$ reported that large amounts of oxygenated compounds were formed at lower temperatures $\left(370{ }^{\circ} \mathrm{C}\right)$ while low gasoline yields with catalyst coking occurred at higher temperatures $\left(410{ }^{\circ} \mathrm{C}\right)$. Furthermore, these unselective catalytic crude bio-oil upgrading processes produced a wide variety of hydrocarbons, including light molecular weight hydrocarbons, which are of less interest.

To obtain high quality fuels with less oxygen contents, a new co-processing ${ }^{139}$ of hydrodeoxygenated (HDO) crude bio-oil with so-called "long residue" oil in a lab-scale fluid catalytic

(1)<smiles>C=CC(C)(C=CC(C)CCC(C)(C)C(=C)CCC(C)C(=C)C)CCCC(C)(C)C(=C)CCC(C)C(=C)C</smiles>

(2)<smiles>Cc1ccc(I)cc1C</smiles>
1<smiles>C[C@H]1C[C@H]1C</smiles>

Fig. 10 Pathways of production of aromatic hydrocarbons from a botryococcene: (1) cracking, and (2) aromatization. Modified from Ref. 149. 
cracking (FCC) fluidized bed reactor has been reported. Under reaction conditions with temperature ranges from 230 to $340{ }^{\circ} \mathrm{C}$ and with total pressure constant at around 290 bar, $5 \mathrm{wt} \%$ of ruthenium supported on carbon powder was used as deoxygenation catalyst. Near oxygenate-free hydrocarbons with more than $40 \mathrm{wt} \%$ of typical FCC gasoline and $20+\mathrm{wt} \%$ of light cycle oil (LCO) and about $10 \%$ of liquefied petroleum gas (LPG) were obtained. However, compared to a pure FCC feed, excessive amounts of undesired coke and dry gas were found in coprocessing experiments, as shown in Fig. 11.

In the literature, direct modeling work has not been published for hydrocracking of algal biofuels. Ancheyta et al. ${ }^{151}$ reviewed the kinetic modeling of hydrocracking of heavy oil fractions. The models were based on the lumping technique, continuous mixtures, structure-oriented lumping and single event, and were all fully discussed and compared in terms of the capacity to predict detailed product composition, difficulty for parameter estimation, dependency of rate coefficient with feed properties, and required experimental data. Recently, Martinez et al. ${ }^{152}$ reviewed the process aspects and modeling of an ebullated bed reactor for hydrocracking of heavy oils. Some key factors for applying these reactors to hydrocracking of heavy petroleum fractions, such as sediment formation, catalyst attrition and catalyst deactivation, were clearly discussed. Here we are summarizing progress in theoretical modelling of mechanisms of catalyzed hydrocracking of heavy compounds.

Based upon the elementary steps of carbenium-ion chemistry, Froment ${ }^{153}$ developed a detailed kinetic model of acid-catalyzed oil-refining processes. In this approach, the computer calculation of the number of events in an elementary step requires knowledge of the configuration of the transition state which could be determined through quantum chemical calculations. Krishna and Balasubramanian ${ }^{154}$ provided a general analytical solution for the full stoichiometry based discrete lumped kinetic equations in hydrocracking of the heavier petroleum fractions. Their results revealed that the full stoichiometry is the best performing model for hydrocracking of heavier petroleum fractions and that the product distribution in a hydrocracker is

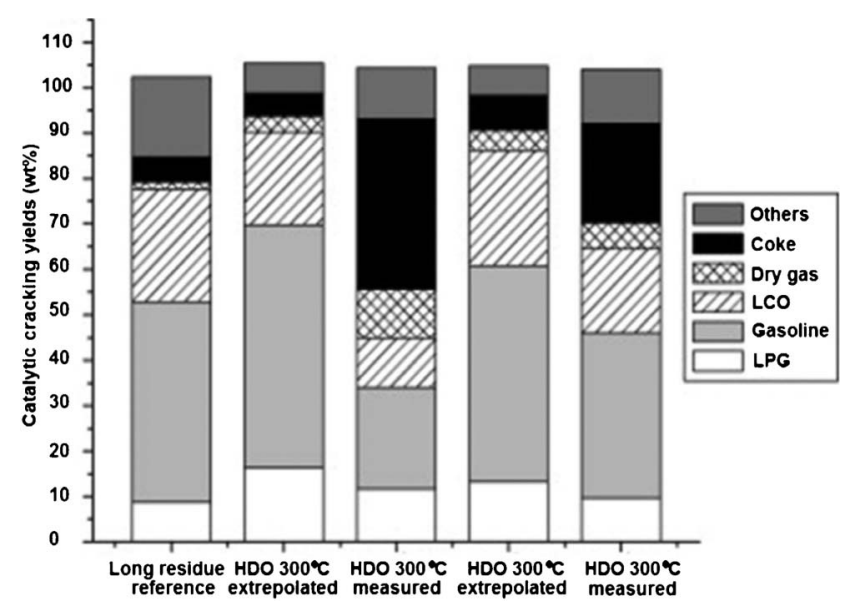

Fig. 11 Product yields after catalytic cracking. Results for experiments denoted as "extrapolated" are theoretical yields obtained when extrapolating actual yields at $20 \mathrm{wt} \%$ mix $\mathrm{HDO}$ oil in long residue to $100 \mathrm{wt} \%$ HDO oil. ${ }^{139}$ governed by ordinary differential equations. Thybaut and Marin ${ }^{155}$ investigated the kinetic modeling of the conversion of complex hydrocarbon feedstocks by acid catalysts and found that the number of elementary reaction families, and hence of the corresponding kinetic parameters, is rather limited, and the variations in acid strength have a significant effect on the activation energy of the acid-catalyzed rearrangement steps. Using the principles of the single-event microkinetic concept, Mitsios et al. ${ }^{156}$ investigated the hydrocracking and hydroisomerization of long-chain paraffin on an amorphous $\mathrm{Pt} / \mathrm{SiO}_{2} \cdot \mathrm{Al}_{2} \mathrm{O}_{3}$ catalyst. Their results showed that the invariant rate constants do not depend on the feedstock composition or the process configuration. From the experimental program involving liquidphase pure n-hexadecane hydrocracking, a complete set of only nine rate constants for paraffin hydrocracking and hydroisomerization were obtained and gave a satisfactory fit of the experimental data.

Zeolite catalysts are often used in hydrocracking processes. According to the bifunctional reaction scheme, kinetic modeling for hydrocracking of alkanes on Pt/US-Y zeolites has been carried out by Martens et al. ${ }^{157}$ and Thybaut et al. ${ }^{158}$ The differences in both the number of acid sites and the average acid length determine the activities of the zeolites. On this catalyst, the reactivity of alkanes increased with the carbon number, which related to three phenomena: (1) the physical sorption of heavier molecules was more favorable; (2) the reaction pathway and the number of parallel reactions became larger with larger molecules; and (3) the stabilization of alkylcarbenium ions and, hence, their concentration, increased with the increasing size and electron-donating property of alkyl-substituents. In order to explore the mechanisms of hydrocarbon conversion in zeolites, several atomistic-level simulations have been done. ${ }^{159-162}$ Based on $a b$ initio quantum chemical calculations, Kazansky et al. ${ }^{161}$ investigated the isobutene cracking on zeolites for three main elementary steps: (1) chain initiation, which resulted in formation of adsorbed carbenium ions by the protonation of olefins by protolytic cracking of paraffins and by protolytic dehydrogenation of paraffins; (2) chain termination, which represented the decomposition of the tert-butoxide group into isobutene and bridging hydroxyl; and (3) chain propagation, which can involve hydride transfer. For each elementary step, at least one transition state was identified. Their calculated heats of reaction and the activation energies of the main elementary steps are comparable with available experimental and other theoretical results. Using the ab initio method at the Hartree-Fock level with an SCF-321G/6-31G* basis set and MP2 perturbation theory, Ridby et $a l .{ }^{162}$ further studied the mechanism of hydrocarbon conversion in zeolites and found that the intermediates are covalent alkoxide species. In their work, the influence of differences in the acid strength on the activation energies was explored. The variations in acid strength were found to only have minor effects on the alkoxide stability and little effect on the activation energies for the $\mathrm{D} / \mathrm{H}$ exchange in methane and for olefin chemisorptions, which have covalent transition states. However, acid strength was found to have a significant effect on the activation energy of the acid-catalyzed rearrangement steps that have ionic transition states. In such cases, all of these activation energies are strongly reduced with increasing acidity. Based on first-principles density functional theory, Frash et al. ${ }^{159}$ explored 
the mechanism of the $\beta$-scission reaction in zeolites and found that the potential energy surface of this reaction is very complex. Three reaction paths were identified: (1) a one-step reaction via the "ringlike" transition state; (2) a two-step $\beta$-scission reaction via a "hydrogen-bonded" transition state and substituted cyclopropane; and (3) a one-step $\beta$-scission reaction via a "hydrogen-bonded" transition state. Among them, path 2 has the lowest activation barrier. Combining experimental measurements with molecular dynamic simulations, Isoda et al. ${ }^{160}$ explored the mechanism of hydrocracking of pyrenes (Py) over nickel-supported Y-zeolite catalysts. Their results showed that pyrene was cracked into 1- and 2-ring aromatics by partial hydrogenation of aromatic rings. Molecular dynamic simulation results indicated that diffusion of the polycyclic aromatic products into the zeolite pore is not easy and that these molecules are cracked on the surface of the zeolite rather than in the pore.

As described above, the first-principles model (FPM) strategies exist in the literature for modeling hydrocracking (HC) reactions with some success, but FPM strategies may not be adequate because of process complexity and common process variations, such as changes in feed composition, operating conditions, and catalyst deactivation. ${ }^{163}$ Obviously, multi-scale modeling approaches are needed to simulate such complex systems. Unfortunately, in the literature information on this kind of multi-scale modeling for hydrocracking is very limited. Bhutani et al. ${ }^{163}$ employed first principles, data-based and hybrid modeling strategies to simulate an industrial hydrocracking unit with comparative performance assessment and to optimize the operation of the industrial HC unit and thereby estimate the costs. Their results demonstrated that the application of data-based and hybrid models to represent the behavior of an industrial $\mathrm{HC}$ unit provides accurate and consistent predictions in the presence of common process variations and changing operating conditions.

\subsection{Deoxygenation of microalgae feedstocks}

After transesterification or hydrolysis, the obtained biodiesel (FAMEs, FFAs) may still contain unsaturated $\mathrm{C}-\mathrm{C}$ bonds and carboxyl groups, depending on the algal lipid composition. These unsaturates will reduce the heat of combustion of the fuel. In some cases, further treatments may be desirable to upgrade the biodiesel by decarboxylation and hydrodeoxygenation processes. ${ }^{164}$ Deoxygenation of FFAs can be categorized into three major reactions: hydrogenation, decarboxylation and decarbonylation. In the presence of $\mathrm{H}_{2}$, the hydrogenation reaction involves the replacement of a hydroxyl group and an oxo group by hydrogen atoms without losing a carbon number, or by removal of the carboxyl group through the release of carbon monoxide to form hydrocarbons having one less carbon number. In the absence of $\mathrm{H}_{2}$, direct decarboxylation or decarbonylation removes the carboxyl group by releasing carbon monoxide or carbon dioxide and producing either a paraffinic hydrocarbon or an olefinic hydrocarbon. Catalytic carbonylations of alkenes and alkynes over transition metal catalysts, especially Pd based catalysts, have been commercially used for the preparation of $\mathrm{C} 5-\mathrm{C} 18$ carboxylic acids and esters. ${ }^{165}$ For the reverse decarbonylation and similar decarboxylation reac- tions, supported Pd catalysts have also been extensively studied. ${ }^{166-171}$

4.3.1 Deoxygenation of FFAs. Noble metals, i.e., Pt and Pd, are typical active hydrogenation catalysts and are also investigated for biomass conversions. Maier et al. ${ }^{167}$ studied gas-phase deoxygenation of carboxylic acids in the presence of $\mathrm{H}_{2}, 97 \%$ heptanes being produced from octanoic acid at $330{ }^{\circ} \mathrm{C}$ over $\mathrm{Pd} /$ $\mathrm{SiO}_{2}$. No alkanes were observed in an inert gas environment. More recently, Murzin's group ${ }^{29,50,168-170,172}$ has extensively studied the heterogeneous deoxygenation of liquid-phase FFAs or similar bio-derived feedstocks for alkane-based biofuels production. The reaction was typically performed in a solvent, such as dodecane or mesitylene, with either $\mathrm{H}_{2}$, diluted $\mathrm{H}_{2}$ or an inert gas in a semibatch reactor using temperature and pressure ranges of $300-360{ }^{\circ} \mathrm{C}$ and 6-40 bar, respectively. The study found that little or no hydrogen is required for the deoxygenation reaction compared to the hydrotreating process. Usually, hydrocarbons with one less carbon than the corresponding fatty acids starting material were the main products, i.e., deoxygenated palmitic acid was transformed to n-pentadecane, while deoxygenated stearic acid produced n-heptadecane. The deoxygenation rates for different fatty acids were found to be independent of carbon number. ${ }^{166}$ Among a variety of supported metal catalysts and metal loadings, a $5 \mathrm{wt} \% \mathrm{Pd} / \mathrm{C}$ catalyst was found to be the most active and selective agent for deoxygenation of stearic acid to n-heptadecane under He. ${ }^{173}$ In addition to deoxygenation of saturated FFAs, ${ }^{29,168,172}$ Murzin et al. ${ }^{169}$ also studied the deoxygenation of unsaturated FFAs and found high product selectivity for the one-less-carbon alkanes. ${ }^{169}$

The reaction pathways for deoxygenation of both saturated and unsaturated $\mathrm{C} 18$ free fatty acids, including stearic, oleic, and linoleic acids have been investigated by Immer et al. ${ }^{174}$ In the presence of inert gas, $\mathrm{He}$, or diluted $\mathrm{H}_{2}$, the reactions were conducted over a $5 \mathrm{wt} \% \mathrm{Pd} / \mathrm{C}$ catalyst in organic solvents in a semi-batch reactor. The major products for catalytic deoxygenation of stearic acid (SA) under He were decarboxylation products, n-heptadecane and heptadecenes. Based on the analysis of $\mathrm{CO}_{2}$ and $\mathrm{H}_{2}$ evolution, they explained that at complete $\mathrm{SA}$ conversion, a $98 \%$ n-heptadecane yield could be reached because of the hydrogenation of heptadecenes via hydrogen transfer from the solvent. However, at low SA conversion, the hydrogenation of heptadecenes was not significant. Similarly, due to the formation of unsaturated products on the catalysts, the reaction requires much more time to reach full conversion under He than in the presence of $\mathrm{H}_{2}$. They also found that the pathway for deoxygenation of the unsaturated $\mathrm{C} 18$ free fatty acids, oleic and linoleic, were consecutively hydrogenated to saturated SA during the heating of the reaction mixture to reaction temperature, followed by subsequent decarboxylation.

Snåre et al. ${ }^{172}$ examined the possible reaction matrix for the deoxygenation of stearic acid in dodecane over metal-supported activated carbon catalysts at $300{ }^{\circ} \mathrm{C}$ and $600 \mathrm{KPa}$ under an inert atmosphere (as shown in Fig. 12). Catalysts were found, under provided conditions, favourable for deoxygenation reactions (decarbonylation and decarboxylation, reactions 1-2), as well as hydrogenation reactions (reactions 3-4). Under hydrogen lean conditions, several side reactions (i.e., isomerization, dehydrogenation, and cyclization, reactions 5-9) were observed. The 


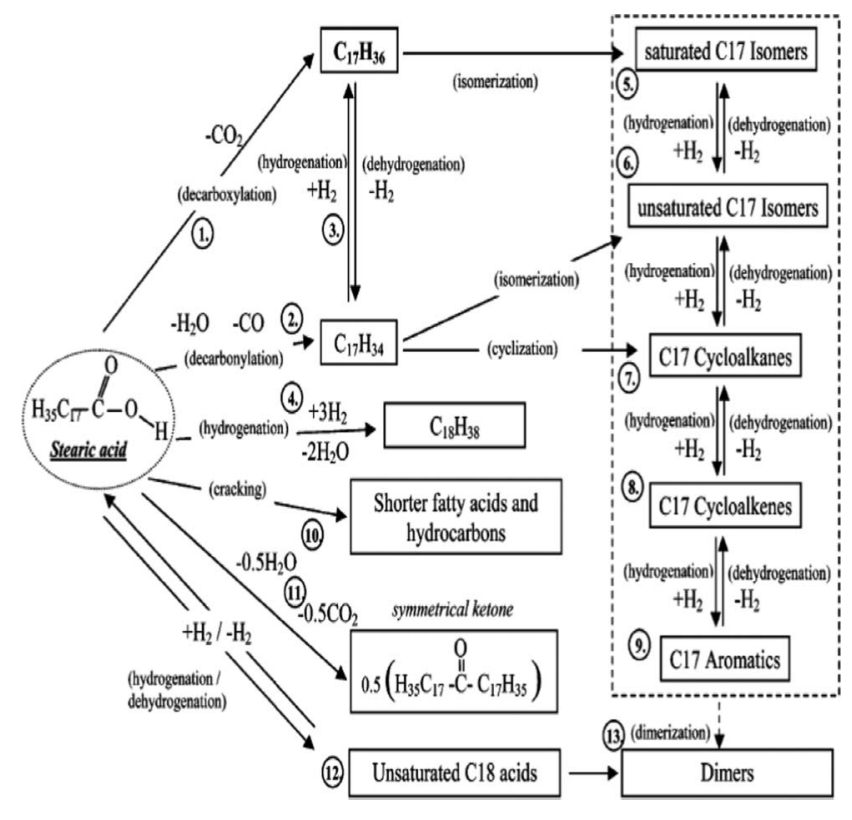

Fig. 12 Tentative reaction routes for deoxygenation of stearic acid over a heterogeneous catalyst at $300{ }^{\circ} \mathrm{C}$ under inert atmosphere. ${ }^{172}$

isomerized $\mathrm{C} 17$ cyclic hydrocarbons and aromatics are subsequent products of these side reactions. Also found in the reaction products were short-chain fatty acids and hydrocarbons, but no fatty alcohols. Therefore, cracking (reaction 10) rather than alcoholation occurred over heterogeneous catalysts under the inert environment, even though alcohol formation via acid hydrogenation is well-known. ${ }^{175}$ To a lesser extent, dimers and heavy products (products of reactions 11-13) were easier to form over nickel catalysts than either Pt- or Pd-supported catalysts. Free hydrogen atoms may be transferred from cracking products or solvents.

4.3.2 Deoxygenation of triglyceride. Some microalgae can accumulate large amounts of triglycerides. Triglycerides can be directly converted to oxygen-lean hydrocarbon fuels via catalytic deoxygenation processes. Precious metal catalysts, including Ni, $\mathrm{Pd}$ and $\mathrm{Pt}$, have been widely used for triglyceride deoxygenation. Morgan et al. ${ }^{176}$ examined the mechanism of triglyceride (tristearin, triolein and soybean oil) deoxygenation over supported $\mathrm{Ni}, \mathrm{Pd}$ and $\mathrm{Pt}$ on activated carbon catalysts. The formation of hydrocarbons spans a range of carbon chain lengths as shown in the following reaction:

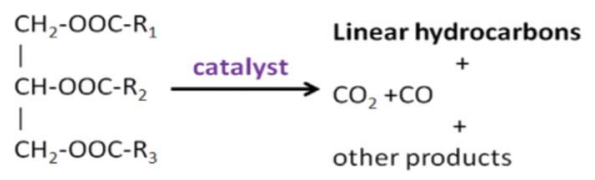

With a Ni catalyst, the conversion of triglyceride produced high yields of linear $\mathrm{C}_{5}$ to $\mathrm{C}_{17}$ alkanes and alkenes, while small amounts of light alkanes $\left(\mathrm{C}_{1}-\mathrm{C}_{4}\right)$ and $\mathrm{H}_{2}$ were also formed. Compared to $\mathrm{Ni}$, catalysts containing $\mathrm{Pd}$ or $\mathrm{Pt}$ supported on activated carbon showed lower activity for both triglyceride deoxygenation and for cracking of the fatty acid chains. ${ }^{176}$ They found that the selectivity towards the cracked and/or hydro-

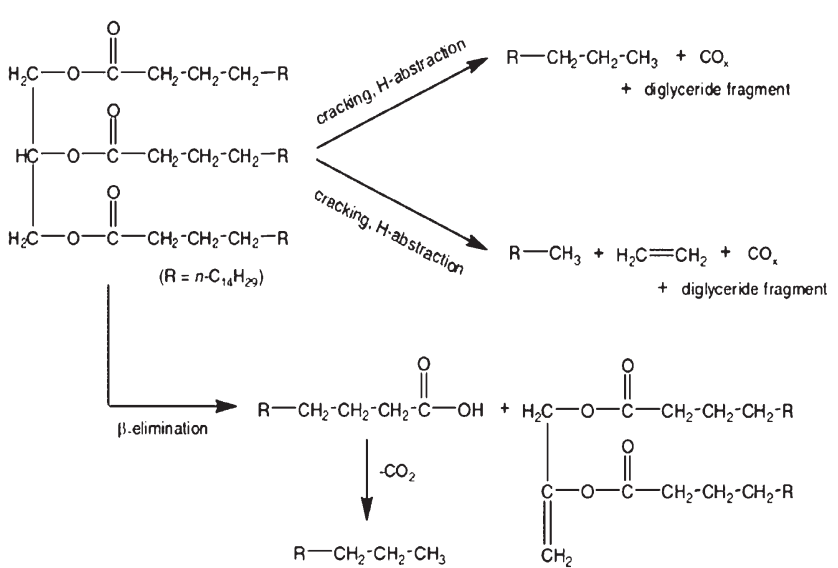

Fig. 13 Simplified reaction scheme for deoxygenation of tristearin. Modified from Ref. 176.

genated products increased with increasing unsaturation of the feed. As shown in Fig. 13, their experimental results suggested that one pathway for triglyceride deoxygenation to $\mathrm{C} 17$ alkanes involves the liberation of fatty acids via $\mathrm{C}-\mathrm{O}$ bond scission, followed by a subsequent step of elimination of $\mathrm{CO}_{2}$ from the acids. Similar results were also reported by Murzin et al., ${ }^{29,168}$ where stearic acid was formed from ethyl stearate as an intermediate, and then it subsequently decarboxylated to the C17 alkane. Alternate pathways for hydrocarbon formation, as both ethene and ethane were detected, involved the scission of the $\mathrm{C}-\mathrm{C}$ bond to $\mathrm{C} 17$ and $\mathrm{C} 15$ hydrocarbons, respectively. This pathway may either correspond to alkanes or terminal alkenes depending on whether hydrogen abstraction occurs during bond scission.

The deoxygenation of triglycerides over $\mathrm{Ni}$, Mo and NiMo sulphide catalysts at $260-280^{\circ} \mathrm{C}, 3.5 \mathrm{MPa}$, and in the presence of $\mathrm{H}_{2}$ in a fixed-bed reactor was investigated. ${ }^{177}$ Significantly different reaction pathways were exhibited over two monometallic supported catalysts, as shown in Fig. 14: the $\mathrm{Ni} / \mathrm{Al}_{2} \mathrm{O}_{3}$ produced only decarboxylation hydrocarbon products, which were also reported by other groups, ${ }^{29,168,176}$ while $\mathrm{Mo} / \mathrm{Al}_{2} \mathrm{O}_{3}$ yielded mainly hydrodeoxygenation of hydrocarbon products. For the bimetallic NiMo catalysts, a mixture of decarboxylation

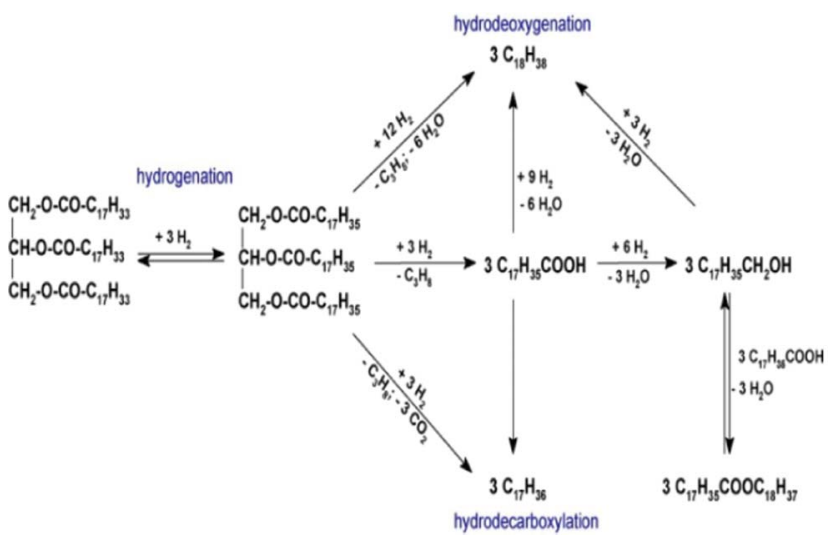

Fig. 14 Reaction pathways involved in conversion of triglycerides into hydrocarbons. ${ }^{177}$ 
and hydrodeoxygenation of hydrocarbon products was found, apart from the various oxygenated product intermediates.

Other liquid-phase catalytic deoxygenation reactions ${ }^{29,169-170}$ were also been investigated for unsaturated renewables (oleic acid, linoleic acid, tristearine and methyl oleate) on a $\mathrm{Pd} / \mathrm{C}$ catalyst and ethyl stearate to produce high carbon number hydrocarbons. With $5 \mathrm{wt} \% \mathrm{Pd} / \mathrm{C}$ catalyst, Immer et al. ${ }^{174}$ explored the catalytic reaction pathways in liquid-phase deoxygenation of $\mathrm{C}_{18} \mathrm{FFAs}$, such as stearic, oleic and linoleic acids, and found that the main liquid products are $n$-heptadecane and heptadecenes. FFA deoxygenation can occur via decarboxylation $\left(\mathrm{C}_{17} \mathrm{H}_{35} \mathrm{COOH} \rightarrow \mathrm{CO}_{2}+n-\mathrm{C}_{17} \mathrm{H}_{36}\right)$ and decarbonylation $\left(\mathrm{C}_{17} \mathrm{H}_{35} \mathrm{COOH} \rightarrow \mathrm{CO}+\mathrm{H}_{2} \mathrm{O}+\mathrm{C}_{17} \mathrm{H}_{34}\right)$ pathways. Thermodynamics of both reactions are favourable at $300{ }^{\circ} \mathrm{C}$ : $\Delta G_{\mathrm{rxn}}=-83.5 \mathrm{~kJ} \mathrm{~mol}^{-1}$ for decarboxylation and $-17 \mathrm{~kJ} \mathrm{~mol}^{-1}$ for decarbonylation. ${ }^{174}$ Snåre et al. ${ }^{170}$ studied the kinetics of ethyl stearate decarboxylation over a $\mathrm{Pd} / \mathrm{C}$ catalyst. Their kinetic modelling and estimated parameters of temperature dependence $\left(300-360{ }^{\circ} \mathrm{C}\right)$ of ethyl stearate decarboxylation fit the experimental results very well with a $99.28 \%$ degree of explanation. Recently, Lei et al. ${ }^{178}$ explored the effect of metal loading for the conversion of fatty acid methyl esters to monoethanolamides. By decreasing the amount of $\mathrm{Al}$ in the layers of the MgAl-layered double hydroxide (LDH) precursors, they found that the conversion of methyl stearate increased dramatically. Therefore, the study and optimizing of metal catalyst compositions will be able to improve and eventually provide effective and feasible routes for algae based bio-diesel production.

4.3.3 Computational simulation of model feedstock. The literature currently provides a limited number of reports involving theoretical modelling of decarboxylation and deoxygenation of algal oil at an atomistic level. Due to limited computer resources, instead of long-chain FFAs from microalgae transesterification or hydrolysis, only short-chain fatty acids or similar small molecules are modelled for such studies. Recently, with first-principles density functional theory, Geatches et al. ${ }^{179,180}$ investigated the decarboxylation reaction of a model fatty acid, $\mathrm{C}_{2} \mathrm{H}_{5} \mathrm{COOH}$, to an alkane $\left(\mathrm{C}_{2} \mathrm{H}_{6}\right)$ with a clay mineral catalyst (pyrophillite with an isomorphic substitution of aluminium in the tetrahedral layer). Fig. 15 shows the schematic of conversion of $\mathrm{C}_{2} \mathrm{H}_{5} \mathrm{COOH}$ to $\mathrm{C}_{2} \mathrm{H}_{6}$ on a clay

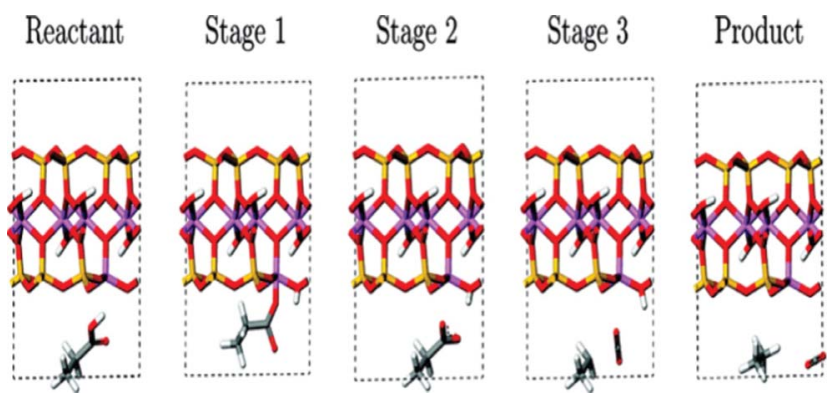

Fig. 15 Schematic of the intermediate stages in a decarboxylation of a model fatty acid $\mathrm{C}_{2} \mathrm{H}_{5} \mathrm{COOH} .{ }^{179}$ Each of the four model sets in this study were geometry optimized from these initial configurations, with the relevant substitution of $\mathrm{Si}$ for $\mathrm{Al}$ and the addition of $\mathrm{Na}$ as described in the text. In the figure, oxygen is red, hydrogen is white, aluminium is pink, carbon is gray and silicon is yellow. mineral catalyst. Their results showed that an uncharged system with a sodium counterion is most feasible for catalyzing the decarboxylation reaction in an Al-substituted pyrophillite and, also, that analysis of the orbitals is a better indicator of a reaction than charge alone.

Based on the use of methyl formate as the model for biodiesel, Metcalfe et al. ${ }^{181}$ investigated the chemical kinetics of methyl formate decomposition by ab intio calculations. Their results indicated that the decomposition is dominated by a single channel producing methanol and $\mathrm{CO}$ over all temperatures. The other two pathways-producing formaldehyde or producing methane and $\mathrm{CO}_{2}$ - are unlikely to occur based on the calculated kinetic mechanism between 500 and $2500 \mathrm{~K}$ and for all pressures. Obviously, these results can be used as the basis to build more realistic models that eventually will provide information for optimizing the efficiency of the production of biofuels.

\section{Perspectives and concluding remarks}

Microalgae has potential as a renewable biomass resource for advanced biofuels and mitigating $\mathrm{CO}_{2}$ emissions because of its high productivity, high oil content, fast growth rates and minimal competition with food crops. ${ }^{14}$ As an alternative fuel, microalgal biodiesel must be competitive with petroleum-derived fuels that are, at present, the least expensive transportation fuels. This will depend mainly on the cost of producing the algal biomass. $5,182,183$ However, for microalgae to be a viable fuel resource it faces challenges of balancing energy inputs, economics and $\mathrm{CO}_{2}$ emission advantages. ${ }^{54,184}$ For 10 million gallons per year of algae lipid production (including algae growth and solvent lipid extraction) with $10 \%$ investment return, it costs $\$ 8.52 /$ gal for an open ponds and \$18.10/gal for closed tubular photobioreactors. Adding the algae lipid conversion to biodiesel through hydrotreating, the corresponding total costs increase to $\$ 9.84 /$ gal and $\$ 20.53 /$ gal based on techno-economic analysis. ${ }^{185}$ Therefore, the current cost of the algae-based biofuel production is much higher than petroleum as well as seed crop-based fuels, mainly due to the energy required for production and processing. ${ }^{184-186}$ The energy consumed primarily in drying algae and extracting lipids from algae comes directly and indirectly from fossil energy (electricity and heat). ${ }^{33,54}$ The high fossil energy input takes away a certain amount of microalgae's $\mathrm{CO}_{2}$ emission advantage from life cycle $\mathrm{CO}_{2}$ analysis. ${ }^{33,54,184}$ To reduce the energy input and lower the cost, one approach is to increase algae lipid content and growth rate. ${ }^{33,185}$ Similarly, developing low cost and low energy intensity harvesting and algae processing technologies are also highly sought. ${ }^{9}$ In addition, value-added co-products (such as animal feed) and co-services (such as water treatment) could also be taken into account for reducing the overall costs. ${ }^{184,185}$

Experimental studies and computational simulations of catalytic conversion for microalgae to transportation fuels are at the early stages of development compared to processes that use other biomass-derived feedstocks. This work has summarized recent progress on the catalytic conversion of microalgaebased biomass to transportation fuels including hydrothermal liquefaction, transesterification and catalytic hydroprocessing methods. Also included is a fundamental understanding of the 
process using computational modelling. Both catalyst development and mechanism modelling strongly impact technological development for microalgae to transportation fuels.

For conversion processes for microalgae, some pioneering work is being performed on the heterogeneous catalytic HTL for algae conversion, but homogeneous catalytic HTL is the current widely used method for processing different microalgae feedstocks. Hydrothermal liquefaction of microalgae to a petroleumequivalent crude oil is considered to be a promising conversion technology. The technology can convert wet and whole microalgae to bio-fuels without the requirement of initially-dry microalgae. Laboratory-scale tests show that hydrothermal liquefaction could convert microalgae with high and low lipid contents and its residues into bio-oil. Catalysts, process conditions and the microalgal species strongly affect the bio-oil yields and properties. However, hydrothermal liquefaction of microalgae faces the challenges of achieving high bio-oil yield, improving the oil quality (e.g. removing nitrogen) and treating/ recycling waste water from the process. Furthermore, during scale up of the process, technical difficulties arise when pumping algae slurry into high pressure reactors and when designing a large reactor because the process involves complex reactions for which mechanisms are not yet clearly understood.

To make the HTL a viable process, extensive research is needed to develop catalysts and new reaction media to increase conversion efficiency and reduce the temperature and pressure of the process while maintaining high reaction rates. Characterization of the products, including primary crude-oil, gas, aqueous phases and algae residues, is necessary for optimizing the catalytic upgrading of crude-oil, generation of high-value co-products and minimization of waste and overall costs. In addition, research on development of heterogeneous catalysts for upgrading bio-crude oil and on the design of advanced processes involving combining bio-fuel production, coproducts and waste recycling are also needed.

Transesterification has a long history in industry and plays an important role in biofuel production as well. Transesterification of algal oil is normally done with alcohol solvents and bases or acids serving as the catalyst. Compared to other catalytic reactions, the transesterification process for biofuel is relatively intolerant to water and FFAs in the feed, especially for homogeneous catalysts. In addition, the complicated posttreatment process also limits the homogeneous catalytic transesterification process. Instead, heterogeneous transesterification catalysts, such as solid acid catalysts, can greatly improve the economics of biodiesel production, without multiple reaction steps and post-treatment steps. Therefore additional attention should be paid to the development of a heterogeneous transesterification process for biofuel production from a microalgae feedstock.

Most of the current research on the catalytic conversion of microalgae to fuels remains in the early stages of studying simple model compounds, C16-C18 FFAs, instead of using more complex lipids from microalgae. Precious metal-supported catalysts have been widely reported for the catalytic conversion of FFAs to linear hydrocarbons. The development of active nonprecious metal catalysts with high selectivity toward green diesel, which are capable of working at mild operating conditions, is a great challenge for microalgae conversion. Chemical solvents, sometimes with $\mathrm{H}_{2}$ under high temperature and pressure, have been applied to these conversion reactions. Novel processes that require less use of $\mathrm{H}_{2}$ and minimal solvents will be a benefit for minimizing the process costs for fuel production. Co-processing of microalgae with other feedstocks in an optimized catalytic commercial process could also help reduce the overall cost.

To provide a feasible cost for the production of green diesel from microalgal lipids, active non-precious metal catalysts with high selectivity toward green diesel, which are also capable of working at mild operating conditions for real microalgae oil, are required. Identifying and optimizing the commercial catalytic petroleum process for microalgae co-feeding can also help reduce the capital investment. Novel processes with decreased usage of $\mathrm{H}_{2}$ and solvents may also be required to minimize the overall cost of fuel production.

In addition, the conversion of by-products from the processes, i.e., glycerol from transesterification and algae residues (mainly protein and carbonhydrates) to high value chemicals, should also be taken into account.

In this review, we summarized the current progress of computational modelling as applied to the catalytic conversion of bio-oil to high-grade biodiesel. Compared with applications in other fields, the computational modelling work performed so far for biodiesel production and upgrading is still very limited. Due to limited computer resources and lack of accumulated knowledge in this relatively new field, most computational modelling work on the catalytic conversion of microalgae has been done on simplified model systems, although such approaches have been successfully applied to other catalyzed chemical reactions. ${ }^{187,188}$ Therefore, more simulation research in this field is expected to be conducted in the future. Further modelling work should be focused on the following aspects:

(1) Although modelling of simplified model systems could provide basic and useful information, direct simulation of algal systems is highly desired. To reach this goal, new and efficient methodologies should be developed that are capable of simulating large real systems.

(2) Catalysts play important roles in biofuel conversion. Identification of the proper catalysts for specific reactions to obtain desired products is difficult solely by experimental methods. Based on known catalysts, computational modelling can screen and identify promising candidates from vast numbers of trial compounds and provide useful information about active sites, optimized structures and composition, and possible synthesis routes. Understanding the mechanisms of catalysts in biofuel conversions is the key issue for improving production processes. Theoretical simulations could provide insight into the catalysis mechanism, especially concerning deactivation, and therefore can guide the experimental research and production process.

(3) Biofuel upgrading involves several process stages. For different stages, one or more modelling schemes can be used. To explore the mechanism and structure, atomistic level ab initio and density functional theory approaches are essential to obtain information about molecular reactivity, structures and the catalytically active sites. To explore the reaction kinetics, a combination of $a b$ initio calculations with molecular dynamic or Monte Carlo simulations can be used to describe the kinetic properties, and the corresponding dependence on temperature 
and pressure. To explore the reactions and mass transfer in reactors, chemical engineering, bioengineering and computational fluid dynamics (CFD) modelling are needed to describe the distributions of products and energy transfer. The parameters used in CFD modelling could also be obtained from atomistic modelling. In order to assess and optimize the entire upgrading process, the multi-scale modelling approach, which combines atomistic level, mesoscale and continuum methods with process modelling is the ultimate approach to simulate biofuel production processes.

\section{Disclaimer}

Reference herein to any specific commercial product, process or service by trade name, trademark, manufacturer or otherwise does not necessarily constitute or imply its endorsement, recommendation or favouring by the United States Government or any agency thereof. The views and opinions of authors expressed herein do not necessarily state or reflect those of the United States Government or any agency thereof.

\section{Acknowledgements}

This work was performed partially in support of the National Energy Technology Laboratory's Office of Research and Development under contract number DE-FE-0004000 with activity number 4000.5.660.251.003. The authors thank Dr S. Chen and Dr D. C. Sorescu for reading part of the manuscript, and appreciate proofreading by J. Fink and C. Wamsley (internal technical writers).

\section{References}

1 EERE, Biomass multi-year program plan, 2012http://www1.eere.energy. gov/biomass/pdfs/mypp_april_2012.pdf.

2 R. Serna-Guerrero, Y. Belmabkhout and A. Sayari, Chem. Eng. Sci., 2010, 65, 4166-4172.

3 Y. Ghasemi, S. Rasoul-Amini, A. T. Naseri, N. MontazeriNajafabady, M. A. Mobasher and F. Dabbagh, Appl. Biochem. Microbiol., 2012, 48, 126-144.

4 R. Luque, J. C. Lovett, B. Datta, J. Clancy, J. M. Campelo and A. A. Romero, Energy Environ. Sci., 2010, 3, 1706-1721.

5 P. T. Pienkos, L. Laurens and A. Aden, American Scientist, 2011, 99, 474-481.

6 M. S. Wigmosta, A. M. Coleman, R. J. Skaggs, M. H. Huesemann and L. J. Lane, Water Resour. Res., 2011, 47, W00H04, DOI: 10.1029/2010WR009966.

7 M. Olivares-Marin, M. Castro-Diaz, T. C. Drage and M. M. Maroto-Valer, Sep. Purif. Technol., 2010, 73, 415-420.

8 EIA, How dependent are we on foreign oil, 2011http://205.254.135.7/ energy_in_brief/foreign_oil_dependence.cfm.

9 DOE-EERE, Algae: 2011 Platform Review Report, 2011http:// www1.eere.energy.gov/biomass/pdfs/2011_algae_review.pdf.

10 EPA, Regulation of Fuels and Fuel Additives: Changes to Renewable Fuel Standard Program, 2010http://www.gpo.gov/fdsys/pkg/FR2010-03-26/pdf/2010-3851.pdf.

$11 \mathrm{H}$. Herzog, E. Drake and E. Adams, $\mathrm{CO}_{2}$ capture, reuse, and storage technologies for mitigating global climate change, $D O E$ Order No. DE-AF22-96PC01257, 1997.

12 R. Pate, G. Klise and B. Wu, Appl. Energy, 2011, 88, 3377-3388.

13 A. F. Clarens, H. Nassau, E. P. Resurreccion, M. A. White and L. M. Colosi, Environ. Sci. Technol., 2011, 45, 7554-7560.

14 F. Bo and W. Q. Liu, Environ. Sci. Technol., 2010, 44, 3640-3640.

15 P. J. L. Williams and L. M. L. Laurens, Energy Environ. Sci., 2010, 3, 554-590.

16 D. H. Lee, Bioresour. Technol., 2011, 102, 43-49.
17 P. H. Pfromm, V. Amanor-Boadu and R. Nelson, Bioresour. Technol., 2011, 102, 1185-1193.

18 A. Singh, P. S. Nigam and J. D. Murphy, Bioresour. Technol., 2011, 102, 10-16.

19 D. J. Stepan, R. E. Shockey, T. A. Moe and R. Dorn, U.S. Department of Energy Report 2002-EERC-02-03, 2002.

20 A. Demirbas and M. F. Demirbas, Energy Convers. Manage., 2011, 52, 163-170

21 T. M. Mata, A. A. Martins and N. S. Caetano, Renewable Sustainable Energy Rev., 2010, 14, 217-232.

22 G. Andrich, U. Nesti, F. Venturi, A. Zinnai and R. Fiorentini, Eur. J. Lipid Sci. Technol., 2005, 107, 381-386.

23 G. Andrich, A. Zinnai, U. Nesti, F. Venturi and R. Fiorentini, Acta Aliment., 2006, 35, 195-203.

24 A. P. Carvalho, L. A. Meireles and F. X. Malcata, Biotechnology Progress, 2006, 22, 1490-1506.

25 Y. Chisti, Biotechnol. Adv., 2007, 25, 294-306.

26 N. Kosaric and J. Velikonja, FEMS Microbiol. Rev., 1995, 16, 111-142.

27 Q. Hu, M. Sommerfeld, E. Jarvis, M. Ghirardi, M. Posewitz, M. Seibert and A. Darzins, Plant J., 2008, 54, 621-639.

28 M. P. Mansour, D. M. F. Frampton, P. D. Nichols, J. K. Volkman and S. I. Blackburn, J. Appl. Phycol., 2005, 17, 287-300.

29 I. Kubickova, M. Snare, K. Eranen, P. Maki-Arvela and D. Y. Murzin, Catal. Today, 2005, 106, 197-200.

30 S. V. Ghadge and H. Raheman, Biomass Bioenergy, 2005, 28, 601-605.

31 N. H. Tran, J. R. Bartlett, G. S. K. Kannangara, A. S. Milev, H. Volk and M. A. Wilson, Fuel, 2010, 89, 265-274.

32 L. Brennan and P. Owende, Renewable Sustainable Energy Rev., 2010, 14, 557-577.

33 H. H. Khoo, P. N. Sharratt, P. Das, R. K. Balasubramanian, P. K. Naraharisetti and S. Shaik, Bioresour. Technol., 2011, 102, $5800-5807$.

34 V. Patil, K. Q. Tran and H. R. Giselrod, Int. J. Mol. Sci., 2008, 9, $1188-1195$.

35 S. Amin, Energy Convers. Manage., 2009, 50, 1834-1840.

36 P. Bondioli, Top. Catal., 2004, 27, 77-82.

37 A. Demirbas, Energy Convers. Manage., 2009, 50, 2782-2801.

38 Z. Y. Du, Y. C. Li, X. Q. Wang, Y. Q. Wan, Q. Chen, C. G. Wang, X. Y. Lin, Y. H. Liu, P. Chen and R. Ruan, Bioresour. Technol., 2011, 102, 4890-4896.

39 R. Li, Z. P. Zhong, B. S. Jin and A. J. Zheng, Energy Fuels, 2012, 26, 2996-3002.

40 H. Fukuda, A. Kondo and H. Noda, Journal of Bioscience and Bioengineering, 2001, 92, 405-416.

41 F. Ma and M. A. Hanna, Bioresour. Technol., 1999, 70, 1-15.

42 B. Smith, H. C. Greenwell and A. Whiting, Energy Environ. Sci, 2009, 2, 262-271.

43 S. Sawayama, S. Inoue, Y. Dote and S. Y. Yokoyama, Energy Convers. Manage., 1995, 36, 729-731.

44 A. A. Peterson, F. Vogel, R. P. Lachance, M. Froling, M. J. Antal and J. W. Tester, Energy Environ. Sci., 2008, 1, 32-65.

45 B. C. Wu, S. Ramon, C. A. DeLuca, E. K. Payne, US Patent No. 0050502,2010

46 M. Koberg and A. Gedanken, Energy Environ. Sci., 2012, 5, $7460-7469$.

47 R. O. Idem, S. P. R. Katikaneni and N. N. Bakhshi, Fuel Process. Technol., 1997, 51, 101-125.

48 A. Leung, D. G. B. Boocock and S. K. Konar, Energy Fuels, 1995, 9, 913-920.

49 T. Kalnes, T. Marker and D. R. Shonnard, Int. J. Chem. React. Eng., 2007, 5, A48.

50 S. Lestari, I. Simakova, A. Tokarev, P. Maki-Arvela, K. Eranen and D. Y. Murzin, Catal. Lett., 2008, 122, 247-251.

51 J. Myllyoja, P. Aalto, P. Savolainen, V. Purola, V. Alopaeus, J. Gronqvist, US Patent US2007/010682 A1, 2007.

52 M. F. Demirbas, Appl. Energy, 2009, 86, S151-S161.

53 D. E. Resasco and S. Crossley, AIChE J., 2009, 55, 1082-1089.

54 S. A. Scott, M. P. Davey, J. S. Dennis, I. Horst, C. J. Howe, D. J. Lea-Smith and A. G. Smith, Curr. Opin. Biotechnol., 2010, 21, 277-286.

55 V. A. Yakovlev, S. A. Khromova, O. V. Sherstyuk, V. O. Dundich, D. Y. Ermakov, V. M. Novopashina, M. Y. Lebedev, O. Bulavchenko and V. N. Parmon, Catal. Today, 2009, 144, 362-366. 
56 S. K. Hoekman, A. Broch, C. Robbins, E. Ceniceros and M. Natarajan, Renewable Sustainable Energy Rev., 2012, 16, 143-169.

57 G. Pokoo-Aikins, A. Nadim, M. M. El-Halwagi and V. Mahalec, Clean Technol. Environ. Policy, 2010, 12, 239-254.

58 H. M. Amaro, A. C. Guedes and F. X. Malcata, Appl. Energy, 2011, 88, 3402-3410.

59 J. Lu, C. Sheahan and P. C. Fu, Energy Environ. Sci., 2011, 4, 2451-2466.

60 J. C. Serrano-Ruiz and J. A. Dumesic, Energy Environ. Sci., 2011, 4, 83-99.

61 A. Melis, Energy Environ. Sci., 2012, 5, 5531-5539.

62 S. P. Zou, Y. L. Wu, M. D. Yang, C. Li and J. M. Tong, Energy Environ. Sci., 2010, 3, 1073-1078.

63 P. G. Duan and P. E. Savage, Bioresour. Technol., 2011, 102, 1899-1906.

64 H. R. Appell, Y. C. Fu, E. G. Illig, F. W. Steffgen, R. D. Miller, Report of Investigations 8013, Washington, DC: Bureau of Mines. 1975.

65 H. R. Appell, J. C. Tosh, US Patent No. 3,733, 255, 1973.

66 S. M. Kohan, Biomass conversion processes for energy and fuels, Plenum Press, New York, 1981.

67 K. S. Ocfemia, Y. Zhang and T. Funk, Transactions of the ASABE, 2006, 49, 1897-1904.

68 Y. Zhang, in Biofuels from Agricultural Wastes and Byproducts, ed. H. P. Blaschek, T. Ezeji and J. Scheffran, Wiley-Blackwell, 2010.

69 D. C. Elliott, Energy Fuels, 2007, 21, 1792-1815.

70 B. J. He, Y. Zhang, T. L. Funk, G. L. Riskowski and Y. Yin, Transactions of the ASAE, 2000, 43, 1827-1833.

71 S. Karagoz, T. Bhaskar, A. Muto and Y. Sakata, J. Chem. Technol. Biotechnol, , 2005, 80, 1097-1102.

72 S. Karagoz, T. Bhaskar, A. Muto and Y. Sakata, Bioresour. Technol., 2006, 97, 90-98.

73 D. Zhou, L. A. Zhang, S. C. Zhang, H. B. Fu and J. M. Chen, Energy Fuels, 2010, 24, 4054-4061.

74 Y. Dote, S. Sawayama, S. Inoue, T. Minowa and S. Yokoyama, Fuel, 1994, 73, 1855-1857.

75 L. G. Alba, C. Torri, C. Samori, J. van der Spek, D. Fabbri, S. R. A. Kersten and D. W. F. Brilman, Energy Fuels, 2012, 26, 642-657.

76 P. Biller and A. B. Ross, Bioresour. Technol., 2011, 102, 215-225.

77 T. M. Brown, P. G. Duan and P. E. Savage, Energy Fuels, 2010, 24, $3639-3646$

78 T. Minowa, S. Yokoyama, M. Kishimoto and T. Okakura, Fuel, 1995, 74, 1735-1738.

79 A. B. Ross, P. Biller, M. L. Kubacki, H. Li, A. Lea-Langton and J. M. Jones, Fuel, 2010, 89, 2234-2243.

80 Y. F. Yang, C. P. Feng, Y. Inamori and T. Maekawa, Resour., Conserv. Recycl., 2004, 43, 21-33.

81 G. Yu, Y. H. Zhang, L. Schideman, T. Funk and Z. C. Wang, Energy Environ. Sci., 2011, 4, 4587-4595.

82 D. R. Vardon, B. K. Sharma, G. V. Blazina, K. Rajagopalan and T. J. Strathmann, Bioresour. Technol., 2012, 109, 178-187.

83 S. P. Zou, Y. L. Wu, M. D. Yang, K. Imdad, C. Li and J. M. Tong, Energy, 2010, 35, 5406-5411.

84 K. Anastasakis and A. B. Ross, Bioresour. Technol., 2011, 102, 4876-4883.

85 D. M. Li, L. M. Chen, D. Xu, X. W. Zhang, N. H. Ye, F. J. Chen and S. L. Chen, Bioresour. Technol., 2012, 104, 737-742.

86 S. Sawayama, T. Minowa and S. Y. Yokoyama, Biomass Bioenergy, 1999, 17, 33-39.

87 S. S. Toor, L. Rosendahl and A. Rudolf, Energy, 2011, 36, 2328-2342.

88 C. Torri, L. G. Alba, C. Samori, D. Fabbri and D. W. F. Brilman, Energy Fuels, 2012, 26, 658-671.

89 U. Jena and K. C. Das, Production of Biocrude Oil from Microalgae via Thermochemical Liquefaction Process, Amer. Soc. Agricultural \& Biological Engineers, St Joseph, 2009.

90 T. O. Matsui, A. Nishihara, C. Ueda, M. Ohtsuki, N. O. Ikenaga and T. Suzuki, Fuel, 1997, 76, 1043-1048

91 G. Yu, Y. Zhang, L. Schideman, T. L. Funk and Z. Wang, Transactions of the ASABE, 2011, 54, 239-246.

92 D. R. Vardon, B. K. Sharma, J. Scott, G. Yu, Z. C. Wang, L. Schideman, Y. H. Zhang and T. J. Strathmann, Bioresour. Technol., 2011, 102, 8295-8303.

93 P. G. Duan and P. E. Savage, Ind. Eng. Chem. Res., 2011, 50, 52-61.
94 P. J. Valdez, J. G. Dickinson and P. E. Savage, Energy Fuels, 2011, 25, 3235-3243.

95 T. Minowa and S. Sawayama, Fuel, 1999, 78, 1213-1215.

96 C. M. Beal, C. H. Smith, M. E. Webber, R. S. Ruoff and R. E. Hebner, BioEnergy Res., 2011, 4, 36-60.

97 B. Cheirsilp, A. H-Kittikun and S. Limkatanyu, Biochem. Eng. J., 2008, 42, 261-269.

98 B. Freedman, R. O. Butterfield and E. H. Pryde, J. Am. Oil Chem. Soc., 1986, 63, 1375-1380.

99 K. Komers, F. Skopal, R. Stloukal and J. Machek, Eur. J. Lipid Sci. Technol., 2002, 104, 728-737.

100 R. Tesser, L. Casale, D. Verde, M. Di Serio and E. Santacesaria, Chem. Eng. J., 2010, 157, 539-550.

101 R. Tesser, L. Casale, D. Verde, M. Di Serio and E. Santacesaria, Chem. Eng. J., 2009, 154, 25-33.

102 A. F. Chang and Y. A. Liu, Ind. Eng. Chem. Res., 2010, 49, 1197-1213.

103 P. G. Cao, A. Y. Tremblay and M. A. Dube, Ind. Eng. Chem. Res., 2009, 48, 2533-2541.

104 M. Canakci and J. Van Gerpen, Transactions of the ASAE, 1999, 42, $1203-1210$

105 B. Liu and Z. Zhao, J. Chem. Technol. Biotechnol., 2007, 82, $775-780$.

106 B. Freedman, E. H. Pryde and T. L. Mounts, J. Am. Oil Chem. Soc., 1984, 61, 1638-1643.

107 K. Ngaosuwan, X. H. Mo, J. G. Goodwin and P. Praserthdam, Top. Catal., 2010, 53, 783-794.

108 M. G. M. D’Oca, P. L. Haertel, D. C. de Moraes, F. J. P. Callegaro, M. H. S. Kurz, E. G. Primel, R. M. Clementin and J. A. MoronVillarreyes, Fuel, 2011, 90, 912-916.

109 M. G. M. D’Oca, C. V. Viegas, J. S. Lemoes, E. K. Miyasaki, J. A. Moron-Villarreyes, E. G. Primel and P. C. Abreu, Biomass Bioenergy, 2011, 35, 1533-1538.

110 X. L. Miao and Q. Y. Wu, Bioresour. Technol., 2006, 97, 841-846.

111 P. D. Patil, V. G. Gude, A. Mannarswamy, P. Cooke, S. MunsonMcGee, N. Nirmalakhandan, P. Lammers and S. G. Deng, Bioresour. Technol., 2011, 102, 1399-1405.

112 A. A. Refaat, S. T. El Sheltawy and K. U. Sadek, IJEST, 2008, 5, 315-322.

113 M. B. Johnson and Z. Y. Wen, Energy Fuels, 2009, 23, 5179-5183.

114 R. Alenezi, G. A. Leeke, J. M. Winterbottom, R. C. D. Santos and A. R. Khan, Energy Convers. Manage., 2010, 51, 1055-1059.

115 P. D. Patil, V. G. Gude, A. Mannarswamy, P. Cooke, N. Nirmalakhandan, P. Lammers and S. G. Deng, Fuel, 2012, 97, 822-831.

116 P. D. Patil, V. G. Gude, A. Mannarswamy, S. G. Deng, P. Cooke, S. Munson-McGee, I. Rhodes, P. Lammers and N. Nirmalakhandan, Bioresour. Technol., 2011, 102, 118-122.

117 A. P. S. Chouhan and A. K. Sarma, Renewable Sustainable Energy Rev., 2011, 15, 4378-4399.

118 S. L. Yan, S. Mohan, C. DiMaggio, M. Kim, K. Y. S. Ng and S. O. Salley, Fuel, 2010, 89, 2844-2852.

119 E. S. Umdu, M. Tuncer and E. Seker, Bioresour. Technol., 2009, 100, 2828-2831.

120 Y. S. Li, S. A. Lian, D. M. Tong, R. L. Song, W. Y. Yang, Y. Fan, R. W. Qing and C. W. Hu, Appl. Energy, 2011, 88, 3313-3317.

121 C. V. McNeff, L. C. McNeff, B. Yan, D. T. Nowlan, M. Rasmussen, A. E. Gyberg, B. J. Krohn, R. L. Fedie and T. R. Hoye, Appl. Catal., A, 2008, 343, 39-48.

122 B. J. Krohn, C. V. McNeff, B. W. Yan and D. Nowlan, Bioresour. Technol., 2011, 102, 94-100.

123 M. Kim, S. O. Salley and K. Y. S. Ng, Energy Fuels, 2008, 22, 3594-3599.

124 Z. Q. Zhang, Y. X. Qu, S. I. Wang and J. D. Wang, J. Mol. Catal. A: Chem., 2010, 323, 91-100.

125 G. M. Turner, E. C. Sherer and G. C. Shields, Int. J. Quantum Chem., 1995, 56, 103-112.

126 E. C. Sherer, G. M. Turner and G. C. Shields, Int. J. Quantum Chem., 1995, 56, 83-93.

127 A. Kubatova, J. St'avova, W. S. Seames, Y. Luo, S. M. Sadrameli, M. J. Linnen, G. V. Baglayeva, I. P. Smoliakova and E. I. Kozliak, Energy Fuels, 2012, 26, 672-685.

128 S. Adhikari, S. D. Fernando and A. Haryanto, Chem. Eng. Technol, 2009, 32, 541-547. 
129 A. Wawrzetz, B. Peng, A. Hrabar, A. Jentys, A. A. Lemonidou and J. A. Lercher, J. Catal., 2010, 269, 411-420.

130 N. Worz, A. Brandner and P. Claus, J. Phys. Chem. C, 2010, 114, $1164-1172$.

131 L. He, J. M. S. Parra, E. A. Blekkan and D. Chen, Energy Environ. Sci., 2010, 3, 1046-1056.

132 P. Gallezot, Catal. Today, 2011, 167, 31-36.

133 T. Yoshikawa, T. Tago, A. Nakamura, A. Konaka, M. Mukaida and T. Masuda, Res. Chem. Intermed., 2011, 37, 1247-1256.

134 D. Ghosh, I. F. Sobro and P. C. Hallenbeck, Bioresour. Technol., 2012, 106, 154-160.

135 D. Ghosh, A. Tourigny and P. C. Hallenbeck, Int. J. Hydrogen Energy, 2012, 37, 2273-2277.

136 L. Zhou, E. Al-Zaini and A. A. Adesina, Fuel, 2012, DOI: 10.1016/ j.fuel.2012.05.042.

137 S. Nitayavardhana and S. K. Khanal, Bioresour. Technol., 2011, 102, 5808-5814.

138 G. Anitescu and T. J. Bruno, Energy Fuels, 2012, 26, 324-348.

139 F. D. Mercader, M. J. Groeneveld, S. R. A. Kersten, N. W. J. Way, C. J. Schaverien and J. A. Hogendoorn, Appl. Catal., B, 2010, 96, 57-66.

140 L. W. Hillen, G. Pollard, L. V. Wake and N. White, Biotechnol. Bioeng., 1982, 24, 193-205.

141 L. W. Hillen, L. V. Wake and D. R. Warren, Fuel, 1980, 59, 446-447.

142 P. Biller, R. Riley and A. B. Ross, Bioresour. Technol., 2011, 102, 4841-4848.

143 N. Akiya and P. E. Savage, Chem. Rev., 2002, 102, 2725-2750.

144 D. Kusdiana and S. Saka, Bioresour. Technol., 2004, 91, 289-295.

145 R. B. Levine, T. Pinnarat and P. E. Savage, Energy Fuels, 2010, 24, $5235-5243$.

146 J. Fu, X. Y. Lu and P. E. Savage, Energy Environ. Sci., 2010, 3, 311-317.

147 J. Fu, F. Shi, L. T. Thompson, X. Y. Lu and P. E. Savage, ACS Catal., 2011, 1, 227-231.

148 M. Watanabe, T. Iida and H. Inomata, Energy Convers. Manage, 2006, 47, 3344-3350.

149 H. Kitazato, S. Asaoka and H. Iwamoto, J. Jpn. Pet. Inst., 1989, 32, 28-34.

150 R. K. Sharma and N. N. Bakhshi, Bioresour. Technol., 1991, 35, 57-66.

151 J. Ancheyta, S. Sanchez and M. A. Rodriguez, Catal. Today, 2005, 109, 76-92.

152 J. Martinez, J. L. Sanchez, J. Ancheyta and R. S. Ruiz, Catal. Rev. Sci. Eng., 2010, 52, 60-105.

153 G. F. Froment, Catal. Today, 1999, 52, 153-163.

154 P. C. Krishna and P. Balasubramanian, Ind. Eng. Chem. Res., 2009, 48, 6608-6617.

155 J. W. Thybaut and G. B. Marin, Chem. Eng. Technol., 2003, 26, $509-514$.

156 M. Mitsios, D. Guillaume, P. Galtier and D. Schweich, Ind. Eng Chem. Res., 2009, 48, 3284-3292.

157 G. G. Martens, G. B. Marin, J. A. Martens, P. A. Jacobs and G. V. Baroni, J. Catal., 2000, 195, 253-267.

158 J. W. Thybaut, G. B. Marin, G. V. Baron, P. A. Jacobs and J. A. Martens, J. Catal., 2001, 202, 324-339.
159 M. V. Frash, V. B. Kazansky, A. M. Rigby and R. A. van Santen, J. Phys. Chem. B, 1998, 102, 2232-2238.

160 T. Isoda, S. Maemoto, K. Kusakabe and S. Morooka, Energy Fuels, 1999, 13, 617-623.

161 V. B. Kazansky, M. V. Frash and R. A. vanSanten, Appl. Catal., A, 1996, 146, 225-247.

162 A. M. Rigby, G. J. Kramer and R. A. vanSanten, J. Catal., 1997, 170, $1-10$.

163 N. Bhutani, G. P. Rangaiah and A. K. Ray, Ind. Eng. Chem. Res., 2006, 45, 7807-7816.

164 P. M. Mortensen, J. D. Grunwaldt, P. A. Jensen, K. G. Knudsen and A. D. Jensen, Appl. Catal., A, 2011, 407, 1-19.

165 A. Brennfuhrer, H. Neumann and M. Beller, Angew. Chem., Int. Ed., 2009, 48, 4114-4133.

166 S. Lestari, P. Maki-Arvela, I. Simakova, J. Beltramini, G. Q. M. Lu and D. Y. Murzin, Catal. Lett., 2009, 130, 48-51.

167 W. F. Maier, W. Roth, I. Thies and P. V. Schleyer, Chem. Ber., 1982, 115, 808-812.

168 P. Maki-Arvela, I. Kubickova, M. Snare, K. Eranen and D. Y. Murzin, Energy Fuels, 2007, 21, 30-41.

169 M. Snare, I. Kubickova, P. Maki-Arvela, D. Chichova, K. Eranen and D. Y. Murzin, Fuel, 2008, 87, 933-945.

170 M. Snare, I. Kubickova, P. Maki-Arvela, K. Eranen, J. Warna and D. Y. Murzin, Chem. Eng. J., 2007, 134, 29-34.

171 M. Snare and D. Y. Murzin, Ind. Eng. Chem. Res., 2006, 45, 6875-6875.

172 M. Snare, I. Kubickova, P. Maki-Arvela, K. Eranen and D. Y. Murzin, Ind. Eng. Chem. Res., 2006, 45, 5708-5715.

173 I. Simakova, O. Simakova, P. Maki-Arvela, A. Simakov, M. Estrada and D. Y. Murzin, Appl. Catal., A, 2009, 355, 100-108.

174 J. G. Immer, M. J. Kelly and H. H. Lamb, Appl. Catal., A, 2010, 375, 134-139.

175 R. L. Augustine, Heterogeneous Catalysis for the Synthetic Chemist, Marcel Dekker, New York, 1996.

176 T. Morgan, D. Grubb, E. Santillan-Jimenez and M. Crocker, Top. Catal., 2010, 53, 820-829.

177 D. Kubicka and L. Kaluza, Appl. Catal., A, 2010, 372, 199-208.

178 X. D. Lei, W. Lu, Q. Peng, H. Y. Li, T. Chen, S. L. Xu and F. Z. Zhang, Appl. Catal., A, 2011, 399, 87-92.

179 D. L. Geatches, S. J. Clark and H. C. Greenwell, J. Phys. Chem. A, 2010, 114, 3569-3575.

180 D. L. Geatches, H. C. Greenwell and S. J. Clark, J. Phys. Chem. A, 2011, 115, 2658-2667.

181 W. K. Metcalfe, J. M. Simmie and H. J. Curran, J. Phys. Chem. A, 2010, 114, 5478-5484.

182 Y. Chisti, Trends Biotechnol., 2008, 26, 126-131.

183 Y. Chisti and J. Y. Yan, Appl. Energy, 2011, 88, 3277-3279.

184 T. Shirvani, X. Y. Yan, O. R. Inderwildi, P. P. Edwards and D. A. King, Energy Environ. Sci., 2011, 4, 3773-3778.

185 R. Davis, A. Aden and P. T. Pienkos, Appl. Energy, 2011, 88, 3524-3531.

186 L. Amer, B. Adhikari and J. Pellegrino, Bioresour. Technol., 2011, 102, 9350-9359.

187 M. Andersson, J. L. Yuan and B. Sunden, Appl. Energy, 2010, 87, 1461-1476.

188 M. Salciccioli, M. Stamatakis, S. Caratzoulas and D. G. Vlachos, Chem. Eng. Sci., 2011, 66, 4319-4355. 